Article

\title{
Structure of Imidazolium-N-phthalolylglycinate Salt Hydrate: Combined Experimental and Quantum Chemical Calculations Studies
}

\author{
Mohammad Usman ${ }^{1}$, Rais Ahmad Khan ${ }^{2, *}$, Mohammad H. Jaafar ${ }^{2}$, Ali Alsalme ${ }^{2}$ aD and \\ Sartaj Tabassum ${ }^{3}$ \\ 1 Department of Chemistry, Indian Institute of Technology-Kanpur, Kanpur 208016, India; \\ mohammadusman148@gmail.com \\ 2 Department of Chemistry, College of Sciences, King Saud University, P.O. Box 2455, Riyadh 11451, \\ Saudi Arabia; mhjaafar@ksu.edu.sa (M.H.J.); aalsalme@ksu.edu.sa (A.A.) \\ 3 Department of Chemistry, Aligarh Muslim University, Aligarh 202002, India; tsartaj62@yahoo.com \\ * Correspondence: krais@ksu.edu.sa
}

Received: 7 January 2020; Accepted: 30 January 2020; Published: 5 February 2020

\begin{abstract}
An organic supramolecular salt hydrate (imidazolium:N-phthalolylglycinate: $\mathrm{H}_{2} \mathrm{O}$; $\left.\mathrm{IM}^{+}-\mathrm{NPG}^{-}-\mathbf{H Y D}\right)$ has been examined for its charge-transfer (CT) characteristics. Accordingly, $\mathbf{I M}^{+}-\mathrm{NPG}^{-}-\mathbf{H Y D}$ has been characterized thoroughly using various spectroscopic techniques. Combined experimental and quantum chemical studies, along with wave function analysis, were performed to study the non-covalent interactions and their role in $\mathrm{CT}$ in the supramolecular salt hydrate. Notably, $\mathbf{I M}^{+}-\mathbf{N P G}^{-}-\mathbf{H Y D}$ crystalizes in two configurations (A and B), both of which are held together via non-covalent interactions to result in a three-dimensional CT supramolecular assembly. The through-space CT occurs from $\mathrm{NPG}^{-}$(donor) to $\mathrm{IM}^{+}$(acceptor), and this was mediated via non-covalent forces. We demonstrated the role of $\pi-\pi$ stacking interactions (mixed-stacking donor-acceptor interactions) in the presence of charge-assisted hydrogen bonds in the regulation of CT properties in the self-assembly of the $\mathbf{I M}^{+}-\mathrm{NPG}^{-}-\mathrm{HYD}$ salt hydrate.
\end{abstract}

Keywords: crystal structure; charge transfer; salt hydrate; Hirshfeld surface; DFT; QTAIM; NBO

\section{Introduction}

The self-assembly characteristics of non-covalent interactions, such as hydrogen bonds, $\pi-\pi$ stacking, and other weak van der Waals forces participating in (bio)chemical processes, have inspired supramolecular chemists to employ them effectively in crystal engineering [1,2]. Crystal engineering is defined as the study of intermolecular interactions in terms of crystal packing and exploiting such kinds of non-covalent interactions for designing multifunctional materials having the desired properties [3,4]. It hasbeen proven that different intermolecular interactions and/or crystal packing could highly modulate the optical and electronic properties of molecular crystals [5]. For example, the formation of multi-component molecular materials (co-crystals, salts, and salt hydrates) has been extensively investigated with the development of crystal engineering or supramolecular chemistry [6-8].

Organic co-crystals, salts, and salt hydrates formed with different molecular moieties through intermolecular non-covalent interactions are attracting the attention of many researchers globally because of their applications in charge transport [9-11], photovoltaics [12], tunable light emitters [13,14], photoconductivity $[15,16]$, ferroelectrics $[17,18]$, nonlinear optics $[19,20]$, light-driven actuators [21], and pharmaceuticals [22]. Moreover, the dynamics of a proton or a hydrogen atom in the H-bonded CT-supramolecular assembly has attracted greater attention, because it plays a crucial role in (bio)chemical reactions and some physical properties, such as dielectricity and proton conductivity [22-25]. 
Hence, a profound understanding of non-covalent interactions and the prediction of their strength are critical to designing the desired functional materials. Remarkably, the physical and chemical properties of co-crystals are not simply the sum of the molecular properties of their constituent molecular moieties [26,27]. In this regard, co-crystallization or crystallization of multi-component molecular systems (co-crystals, salts, and salt hydrates) opens the door not only for the development of new multifunctional materials but also for the examination of novel phenomenon such as charge-transfer along the molecular crystallographic axis $[28,29]$.

In 1952, Mulliken laid the foundation stone of the concept of charge transfer (CT) [30]. He observed new absorption bands for multicomponent molecular complexes; these bands were absent from the spectra of any of the constituent components individually. In addition, these molecular complexes contain an electron-donor component and an electron-acceptor component with low ionization energy and high electron affinity, respectively. Such type of multicomponent molecular complexes has an ionic excited state $\left(\psi_{1}=\mathrm{D}^{+} \ldots \mathrm{A}^{-}\right)$with comparatively low excitation energy, and mixing this state with the neutral ground state $\left(\psi_{0}=\mathrm{D} \cdots \mathrm{A}\right)$ results in $\psi_{0}+\lambda \psi_{1}$ and $\psi_{1}-\lambda \psi_{0}$ states. The transition dipole moment between these states is very large, resulting in strong electronic absorption; this transition dipole moment cannot occur in isolated components, be it an isolated donor or an isolated acceptor. Strikingly, the mixing of the molecular components results in color change because of the low excitation energy that may lie in the visible region of the spectrum. Mulliken observed that the mixing must lower the energy of the complex relative to the energy of the state $\psi_{0}$ : a charge-transfer contribution to the interaction energy. Hence, the CT interaction is the consequence of the charge density being transferred from the electron-donor component to the electron acceptor component, and the charge-transfer energy is the lowering in the energy associated with this transfer. Therefore, regarding the above-described Mulliken's CT concept and crystal-engineering concept, we combine both the concepts to achieve the desired charge-transfer complex.

In this study, we prepare a charge-transfer $\mathbf{I M}^{+}-\mathbf{N P G}^{-}-\mathbf{H Y D}$ with mixed-stacking and charge-assisted hydrogen bonds between $\mathrm{IM}^{+}$and $\mathrm{NPG}^{-}$moieties. The proton transfer occurred from the carboxylic group of NPG to the amine group of IM, resulting in a charge-assisted hydrogen bond between both the moieties [31]. Generally, charge-assisted hydrogen bonding is stronger than normal hydrogen bond because of the presence of additional electrostatic interactions; consequently, the molecular components act as charge carriers. Nevertheless, charge-assisted hydrogen bonds have not been studied much as a designing factor in the self-assembly process of supramolecular entities [32-37]. There is still much scope for developing, understanding, and implementing charge-assisted hydrogen bonds in the context of crystal engineering.

\section{Result and Discussion}

\subsection{Spectroscopic Analysis}

A shift in the vibrational frequency of the multi-component molecular crystal with respect to the individual molecular entities denotes the formation of new hydrogen bonds and other weak noncovalent forces [38-40]. As depicted in Figure S1, from the IR spectrum of NPG, carbonyl stretching frequencies of the carboxylic acid are observed at 1724.17 and $1415.18 \mathrm{~cm}^{-1}$. The carbonyl stretching bands were the most distinctive IR features to distinguish the carboxylic acid group from the conjugate carboxylate moiety $[41,42]$. The asymmetric and symmetric stretching frequencies of the carboxylate group $\left(\mathrm{COO}^{-}\right)$ were observed at 1708.60 and $1419.98 \mathrm{~cm}^{-1}$, respectively. Significant shifts in these vibrational frequencies were observed in $\mathbf{I M}^{+}-\mathbf{N P G}^{-}-\mathbf{H Y D}$ (see Figure S1 in Supplementary Materials), signifying the proton transfer from the carboxylic-acid group [43]. A further relevant observation is that the IR spectrum of the $\mathbf{I M}^{+}-\mathrm{NPG}^{-}-\mathbf{H Y D}$ salt displayed a characteristic band at the $3502.27 \mathrm{~cm}^{-1}$, revealing the $v_{\mathrm{OH}}$ stretching frequency of hydrogen-bonded lattice water [44]. Furthermore, the vibrational frequencies have also been calculated to support and assign the mode of vibration, observed experimentally. The IR spectrum has been simulated using DFT/M062X/6-31G** method given in Figure S2. The calculated 
frequencies and other spectral features were found to be within the range, shown in Table 1. Three factors could be responsible for the deviation in the computed spectrum: (1) the environmental factor as DFT calculations were performed with solvation effect (liquid phase, EtOH as solvent) while experimental data was obtained at solid-state; (2) the calculated frequencies are included only harmonic while experimental have both harmonic and anharmonic effect; and (3) basis set and DFT functional discrepancies. However, the pattern and trend of spectra were quite similar in both the cases which support the experimental observations.

Table 1. Some selected experimental and calculated frequencies $\left(\mathrm{cm}^{-1}\right)$ of $\mathbf{I M}^{+}-\mathrm{NPG}^{-}-\mathbf{H Y D}$ salt.

\begin{tabular}{lcc}
\hline \multicolumn{1}{c}{ Vibrational Mode } & Experimental & Calculated \\
\hline$v_{\mathrm{SV}}(-\mathrm{OH})$ & 3502.27 & 3636 \\
$v_{\mathrm{SV}}(-\mathrm{NH})$ & 3410.16 & 3502 \\
$v_{\mathrm{SV}}(-\mathrm{CH})$ & 3173.10 & 3249 \\
$v_{\mathrm{SV}}(-\mathrm{CH})$ & 2934.58 & 3007 \\
$v_{\mathrm{SV}}(-\mathrm{C}=\mathrm{O})$ & 1774.59 & 1745 \\
$v_{\mathrm{av}}(-\mathrm{O}-\mathrm{C}=\mathrm{O})$ & 1708.60 & 1710 \\
$v_{\mathrm{SV}}(-\mathrm{O}-\mathrm{C}=\mathrm{O})$ & 1419.98 & 1426 \\
\hline
\end{tabular}

sv, symmetrical stretching; av, anti-symmetrical stretching.

To examine IM and NPG, as well as the self-assembly and molecular recognition in the solution phase, tandem mass-spectroscopy (ESI-MS/MS) was performed. A m/z 294.1 molecular ion peak, which is precisely matched with the sum of the $\mathbf{I M}^{+}-\mathbf{N P G}^{-}-\mathbf{H Y D}$ salt's hydrate, $\left[\mathrm{C}_{13} \mathrm{H}_{13} \mathrm{~N}_{3} \mathrm{O}_{5}+3 \mathrm{H}^{+}\right]$, was designated as the primary ion in the first stage (Figure S3).

The UV-vis spectra of IM, NPG, and $\mathbf{I M}^{+}-\mathrm{NPG}^{-}-\mathbf{H Y D}$ salt hydrate were recorded in the solution state $\left(\mathrm{EtOH}, 1 \times 10^{-4} \mathrm{M}\right)$ to explore the possibility of CT interaction between the NPG- and $\mathrm{IM}^{+}$ molecular entities within the $\mathbf{I M}^{+}-\mathbf{N P G}^{-}-\mathbf{H Y D}$ salt hydrate (Figure 1). The absorption spectrum of the $\mathbf{I M}^{\mathbf{+}}-\mathbf{N P G}^{-}-\mathbf{H Y D}$ salt hydrate is characterized by the appearance of a new absorption band in the visible region (380-550 nm). Neither NPG nor IM displayed any absorption band in this region. Therefore, this new absorption band in the visible region (380-550 nm) is attributed to the formation of donor-acceptor charge transfer IM+-NPG--HYD salt hydrate [45-48]. In comparison to UV-vis spectra of IM, NPG, and IM+-NPG --HYD salt hydrate, a remarkable bathochromic shift in the absorption bands appeared in the region of $250-350 \mathrm{~nm}$ is also observed in $\mathbf{I M}^{+}-\mathbf{N P G}^{-}-\mathbf{H Y D}$ salt hydrate. The observed significant bathochromic shift in the 250-350 $\mathrm{nm}$ absorption band is also indicated the charge transfer nature of the $\mathbf{I M}^{+}-\mathrm{NPG}^{-}-\mathbf{H Y D}$ salt hydrate [45-48]. Furthermore, TDDFT calculation has been carried out at the cam-B3LYP/cc-pVTZ level of theory to calculate the vertical excitation energies and oscillator strengths of the electronic transition. The TDDFT simulated UV-vis spectrum (vertical excitation energies and oscillator strengths) of $\mathbf{I M}^{\mathbf{+}}-\mathbf{N P G}^{-}-\mathbf{H Y D}$ salt hydrate is in good agreement with the experimental spectrum. The TDDFT results suggested that a broad CT band in the range of 400-550 nm, comprises $\mathrm{CT}_{0} \rightarrow \mathrm{CT}_{1}, \mathrm{CT}_{0} \rightarrow \mathrm{CT}_{2}, \mathrm{CT}_{0} \rightarrow \mathrm{CT}_{3}$, and $\mathrm{CT}_{0} \rightarrow \mathrm{CT}_{4}$ electronic transitions located at 430, 446, 513, and $534 \mathrm{~nm}$, respectively (Figure 1). The vertical excitation energies for electronic transitions $\mathrm{CT}_{0} \rightarrow \mathrm{CT}_{1}$, $\mathrm{CT}_{0} \rightarrow \mathrm{CT}_{2}, \mathrm{CT}_{0} \rightarrow \mathrm{CT}_{3}$, and $\mathrm{CT}_{0} \rightarrow \mathrm{CT}_{4}$ were found to be 1.72, 1.79, 2.06, and $2.14 \mathrm{eV}$, respectively. Moreover, the molecular orbitals involved in the electronic transitions $\mathrm{CT}_{0} \rightarrow \mathrm{CT}_{1}, \mathrm{CT}_{0} \rightarrow \mathrm{CT}_{2}, \mathrm{CT}_{0} \rightarrow$ $\mathrm{CT}_{3}$, and $\mathrm{CT}_{0} \rightarrow \mathrm{CT}_{4}$ were found to be $\mathrm{HOMO} \rightarrow \mathrm{LUMO}, \mathrm{HOMO}-2 \rightarrow \mathrm{LUMO}, \mathrm{HOMO} \rightarrow \mathrm{LUMO}+1$, and $\mathrm{HOMO}-1 \rightarrow \mathrm{LUMO}+1$ excitations, respectively [48]. The detail description of the CT transfer nature of the $\mathbf{I M}^{+}-\mathrm{NPG}^{-}-\mathbf{H Y D}$ salt hydrate is given in Section 2.5 . 


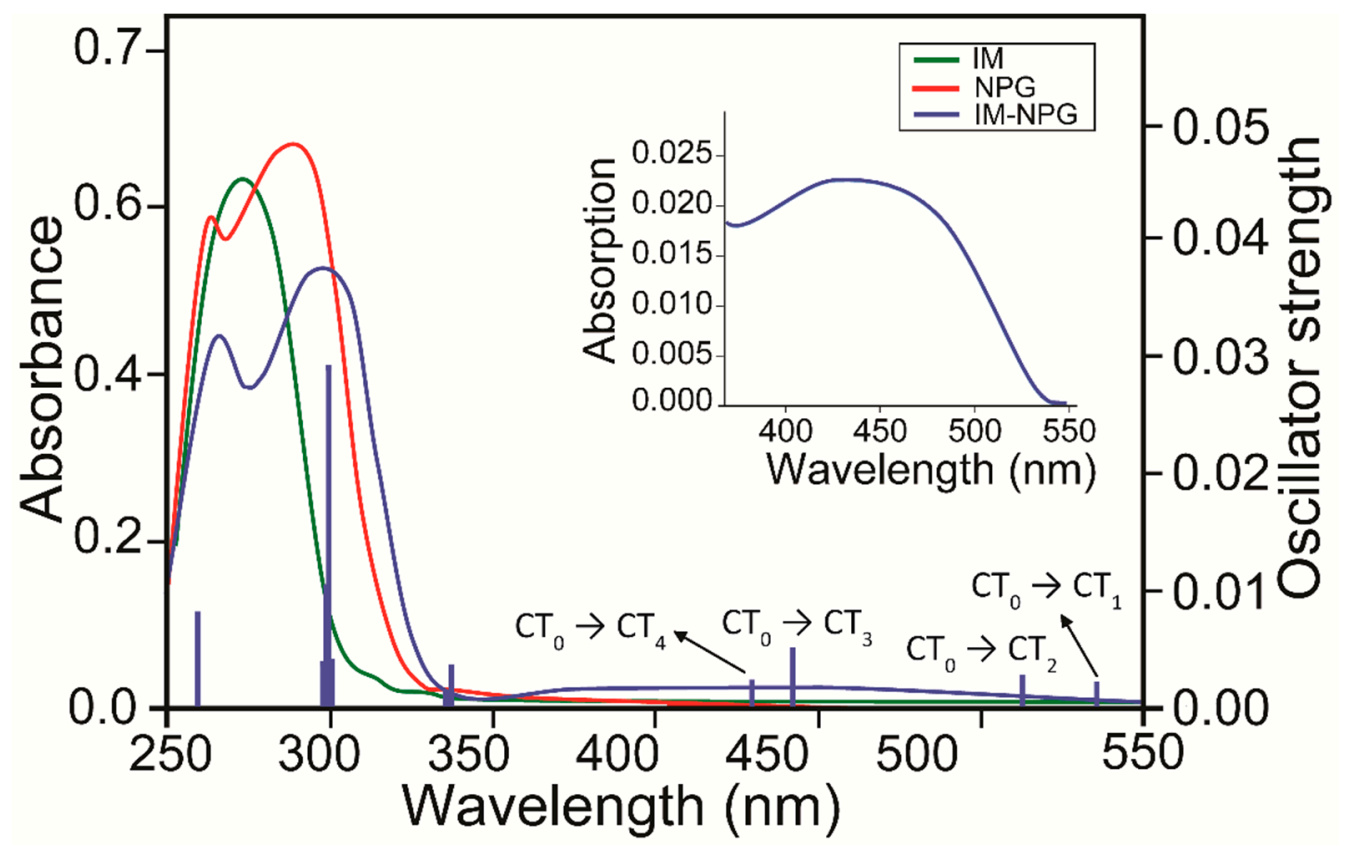

Figure 1. Absorption spectra (curved line, left axis) of IM, NPG, and $\mathbf{I M}^{+}-\mathrm{NPG}^{-}-\mathbf{H Y D}$ in EtOH $\left(1 \times 10^{-4} \mathrm{M}\right)$ and oscillator strengths (vertical line, right axis) obtained from TD-DFT calculations at the cam-B3LYP/cc-pVTZ level of theory. The expanded view of experimentally observed broad CT- band

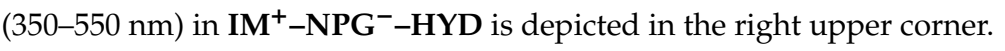

The ${ }^{1} \mathrm{H}$ NMR spectra of NPG, IM, and $\mathbf{I M}^{+}-\mathbf{N P G}^{-}-\mathbf{H Y D}$ were recorded in DMSO- $\mathrm{d}_{6}$ solution and depicted in Figure 2. The ${ }^{1} \mathrm{H}$ NMR spectrum of NPG exhibited signals at 4.31, 7.85-7.93, and 13.25 ppm, attributed to the protons of the $-\mathrm{CH}_{2}$, aromatic ring, and $-\mathrm{COOH}$ group, respectively. In the ${ }^{1} \mathrm{H}$ NMR spectrum of IM, signals exhibited at 7.01-7.64 ppm are attributed to the aromatic protons of the ring, while an upfield signal appeared at $12.07 \mathrm{ppm}$ is attributed to the $-\mathrm{NH}$ proton. Compared with the free NPG and IM ${ }^{1} \mathrm{H}$ NMR spectra, a significant peak shift was observed in the spectrum of $\mathbf{I M}^{+}-\mathbf{N P G}^{-}-\mathbf{H Y D}$, indicating the existence of hydrogen bonds and other noncovalent interactions also in the solution phase. A broad signal with low intensity at $11.90 \mathrm{ppm}$ in $\mathbf{I M}^{+}-\mathbf{N P G}^{-}-\mathbf{H Y D}$ is attributed to the $-\mathrm{NH}$ proton. Additionally, ${ }^{1} \mathrm{H}$ NMR spectrum for salt hydrated simulated theoretically using DFT/B3LYP/6-311 + $\mathrm{G}(2 \mathrm{~d}, \mathrm{p})$ and PBE0/Def2-TZVPP methods to assign the experimentally observed ${ }^{1} \mathrm{H}$ NMR signals. The simulated ${ }^{1} \mathrm{H}$ NMR spectrum at PBE0/Def2-TZVPP level of theory is found to be in good match with the experimental one with a slight deviation. This deviation could be attributed to the absence of a solvation effect in the calculated shielding values (gas-phase) whereas the experimental values recorded in the solution phase.

(a)

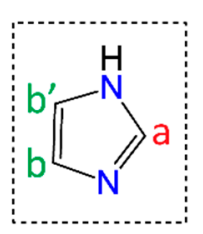

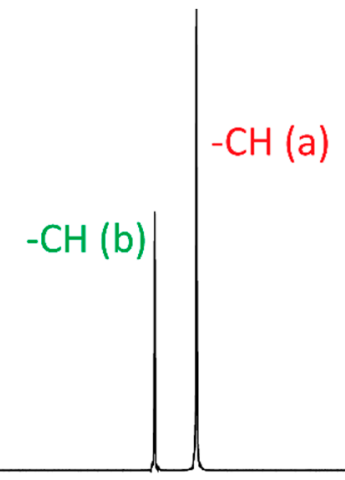

Figure 2. Cont. 


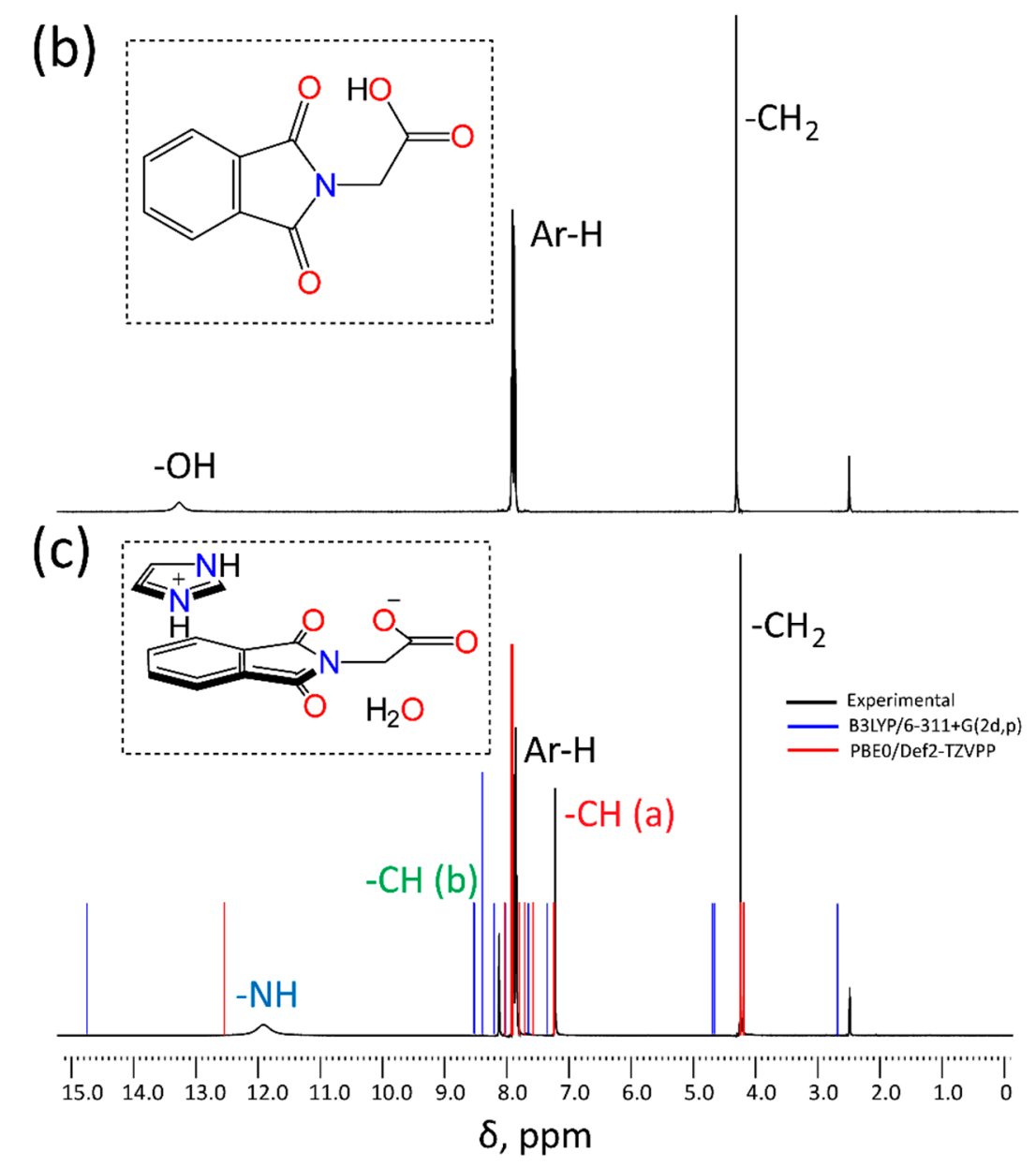

Figure 2. ${ }^{1} \mathrm{H}$ NMR spectra (in $\mathrm{d}^{6}$-DMSO at $295 \mathrm{~K}$ ) of (a) IM, (b) NPG, and (c) $\mathrm{IM}^{+}-\mathrm{NPG}^{-}-\mathrm{HYD}$. The DFT calculated chemical shielding (ppm) for $\mathbf{I M}^{+}-\mathbf{N P G}^{-}-\mathbf{H Y D}$ protons are shown in blue and red vertical lines.

\subsection{Crystal Structure of $I M^{+}-N P G^{-}-H Y D(1: 1: 1)$}

The $\mathbf{I M}^{+}-\mathbf{N P G}^{-}-\mathbf{H Y D}$ salt was block-shaped and crystallized in the monoclinic $\mathrm{C} 2 / \mathrm{c}$ space group. The asymmetric unit consists of an $\mathrm{NPG}^{-}$, an $\mathrm{IM}^{+}$and a water molecule (see Figure 3), and the crystal packing is depicted in Figure S4. The details of bond distances, hydrogen bonds, structure refinement, and crystal data were presented in Tables 2 and 3. The C-O distances in the C10-O3 and C10-O4 of the carboxylic acid group in NPG are 1.243(3) and 1.264(3) $\AA$, respectively, indicating the presence of a deprotonated form of NPG in the $\mathbf{I M}^{+}-\mathbf{N P G}^{-}-\mathbf{H Y D}$ salt hydrate. There are two configurations, $\mathbf{A}$ and $\mathbf{B}$, present in the supramolecular assembly of $\mathbf{I M}^{+}-\mathbf{N P G}^{-}-\mathbf{H Y D}$. Both these configurations are held together through the water molecule via hydrogen bonds. In configuration $\mathbf{A} \mathrm{IM}^{+}$and $\mathrm{NPG}^{-}$molecules are arranged alternatively and stacked on each other through $\pi-\pi$ interactions

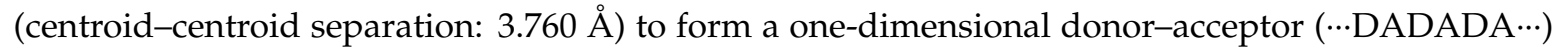
CT-chain (Figure 4a). In configuration $\mathbf{B}, \mathrm{NPG}^{-}$is linked to $\mathrm{IM}^{+}$and $\mathrm{H}_{2} \mathrm{O}$ by hydrogen bonds, further self-assembling alternatively to each other to form a one-dimensional donor-acceptor CT-chain.

Furthermore, these one-dimensional CT-chains are perpendicular to each other and connected with a water molecule via $\mathrm{N} 2-\mathrm{H} 2 \cdots \mathrm{O} 4, \mathrm{~N} 3-\mathrm{H} 3 \mathrm{~A} \cdots \mathrm{O} 1 \mathrm{~W}, \mathrm{O} 1 \mathrm{~W}-\mathrm{H} 1 \mathrm{WB} \cdots \mathrm{O} 3$, and $\mathrm{O} 1 \mathrm{~W}-\mathrm{H} 1 \mathrm{WA} \cdots \mathrm{O} 2$ hydrogen bonds, resulting in 3D supramolecular CT assembly (Figure 5). Furthermore, geometry optimizations of both the configurations have been carried out at the DFT level of theory using the M06-2X/6-31G ${ }^{* *}$ method and in good agreement with the crystal structure data. The calculated bond distances and the distances between $\mathrm{IM}^{+}$and $\mathrm{NPG}^{-}$are given in Table 1. Slight deviation observed 
in the calculated structure observed due to the fact that the DFT calculation performed in solvent phase EtOH as a solvent using the CPCM solvation method while experimental data collected from the solid-state material (Figure S5). We have also calculated the interfragmentary interaction energy from the Hirshfeld charges and depicted in Figure 4.

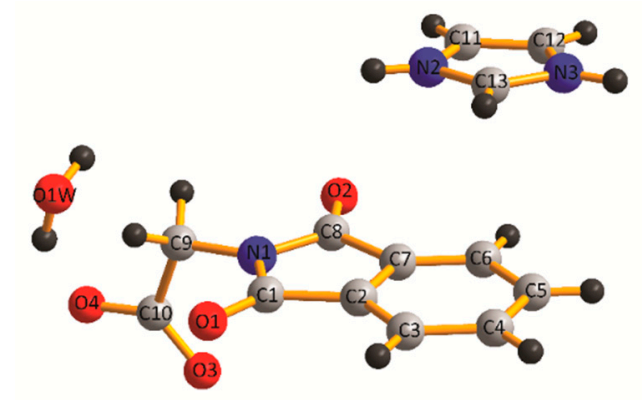

Figure 3. Crystal structure with the label of $\mathbf{I M}^{+}-\mathrm{NPG}^{-}-\mathrm{HYD}$.

Table 2. Single-crystal X-ray determined, and DFT calculated bond Lengths in $\AA$ for $\mathrm{IM}^{+}{ }_{-} \mathrm{NPG}^{-}$-HYD.

\begin{tabular}{cccccccc}
\hline Bond & \multicolumn{2}{c}{ DFT } & X-ray & Bond & \multicolumn{2}{c}{ DFT } & X-ray \\
\hline & Conf. A & Conf. B & & & Conf. A & Conf. B \\
\hline O1-C1 & 1.20911 & 1.20774 & $1.207(3)$ & C1-C2 & 1.49332 & 1.49195 & $1.487(3)$ \\
O2-C8 & 1.21626 & 1.20817 & $1.213(3)$ & C2-C3 & 1.38389 & 1.38260 & $1.384(3)$ \\
O3-C10 & 1.24804 & 1.22823 & $1.243(3)$ & C2-C7 & 1.39069 & 1.39056 & $1.386(3)$ \\
O4-C10 & 1.25007 & 1.28972 & $1.264(3)$ & C3-C4 & 1.39878 & 1.39831 & $1.391(4)$ \\
N1-C1 & 1.38606 & 1.40023 & $1.392(3)$ & C4-C5 & 1.39823 & 1.39655 & $1.391(4)$ \\
N1-C8 & 1.40031 & 1.39845 & $1.381(3)$ & C5-C6 & 1.39897 & 1.39694 & $1.392(4)$ \\
N1-C9 & 1.44965 & 1.43814 & $1.448(3)$ & C6-C7 & 1.38346 & 1.38324 & $1.374(4)$ \\
N2-C11 & 1.37802 & 1.37584 & $1.373(3)$ & C7-C8 & 1.49368 & 1.49164 & $1.497(3)$ \\
N2-C13 & 1.32984 & 1.32155 & $1.325(3)$ & C9-C10 & 1.56229 & 1.53819 & $1.526(4)$ \\
N3-C12 & 1.37684 & 1.37268 & $1.370(3)$ & C11-C12 & 1.35969 & 1.36419 & $1.344(4)$ \\
N3-C13 & 1.32869 & 1.34207 & $1.322(3)$ & & & & \\
IM $^{+} .$. NPG $^{-}$ & 3.23483 & & $3.359(3)$ & & & & \\
IM $^{+} .$. NPG $^{-}$ & & 2.45662 & $2.665(3)$ & & & & \\
\hline
\end{tabular}

Table 3. Hydrogen bonds in $\mathrm{IM}^{+}-\mathrm{NPG}^{-}-\mathrm{HYD}$.

\begin{tabular}{|c|c|c|c|c|}
\hline D-H $\cdots A$ & 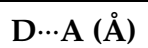 & 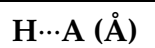 & D-H $\cdots A$ (deg) & Symmetry Code \\
\hline $\mathrm{O} 1 \mathrm{~W}-\mathrm{H} 1 \cdots \mathrm{O} 2$ & $2.9249(5)$ & 2.13 & 152 & \multirow{4}{*}{$\frac{1}{2}-x, 1 / 2-y, 1-z$} \\
\hline $\mathrm{N} 2-\mathrm{H} 2 \cdots \mathrm{O} 4$ & $2.6577(4)$ & 1.81 & 167 & \\
\hline O1W-H1…3 & $2.7059(5)$ & 1.84 & 173 & \\
\hline N3-H3A… 1 WW & $2.7525(5)$ & 1.98 & 150 & \\
\hline 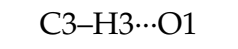 & $3.3427(6)$ & 2.47 & 157 & \multirow{5}{*}{$\begin{array}{c}x, 1-y, 1 / 2+z \\
\frac{1}{2}-x,-\frac{1}{2}+y, 1 / 2-z \\
x, 1-y, 1 / 2+z \\
-x, y, 1 / 2-z \\
x,-1+y, z\end{array}$} \\
\hline C9-H9A…O1 & $3.4578(6)$ & 2.51 & 164 & \\
\hline $\mathrm{C} 11-\mathrm{H} 11 \cdots \mathrm{O} 3$ & $3.4064(6)$ & 2.54 & 156 & \\
\hline $\mathrm{C} 12-\mathrm{H} 12 \cdots \mathrm{O} 2$ & $3.4421(6)$ & 2.55 & 161 & \\
\hline $\mathrm{C} 13-\mathrm{H} 13 \cdots \mathrm{O} 4$ & $3.1838(5)$ & 2.27 & 166 & \\
\hline
\end{tabular}


(a)

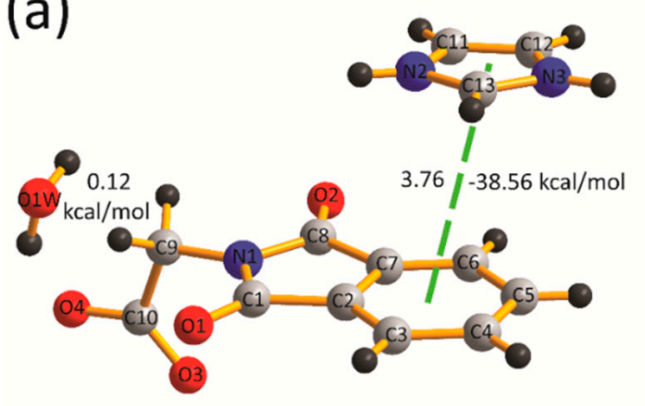

(b)

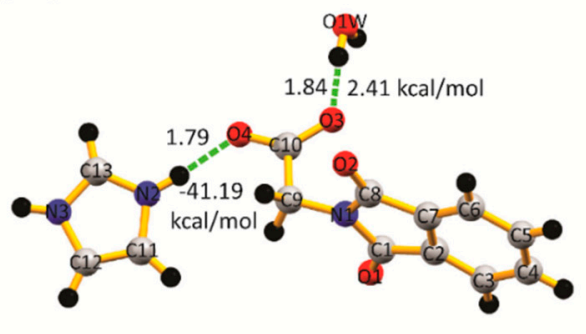

Figure 4. Two different configurations of $\mathbf{I M}^{+}-\mathbf{N P G}^{-}-\mathbf{H Y D}$ in the supramolecular assembly: (a) A and (b) B. Distances of $\pi-\pi$ stacking and hydrogen bonds are in angstrom, and the green line depicts the hydrogen bonds. The interfragmentary interaction energy between each $\mathrm{IM}^{+}, \mathrm{NPG}^{-}$, and $\mathrm{H}_{2} \mathrm{O}$ moieties is calculated via Hirshfeld charge analysis.
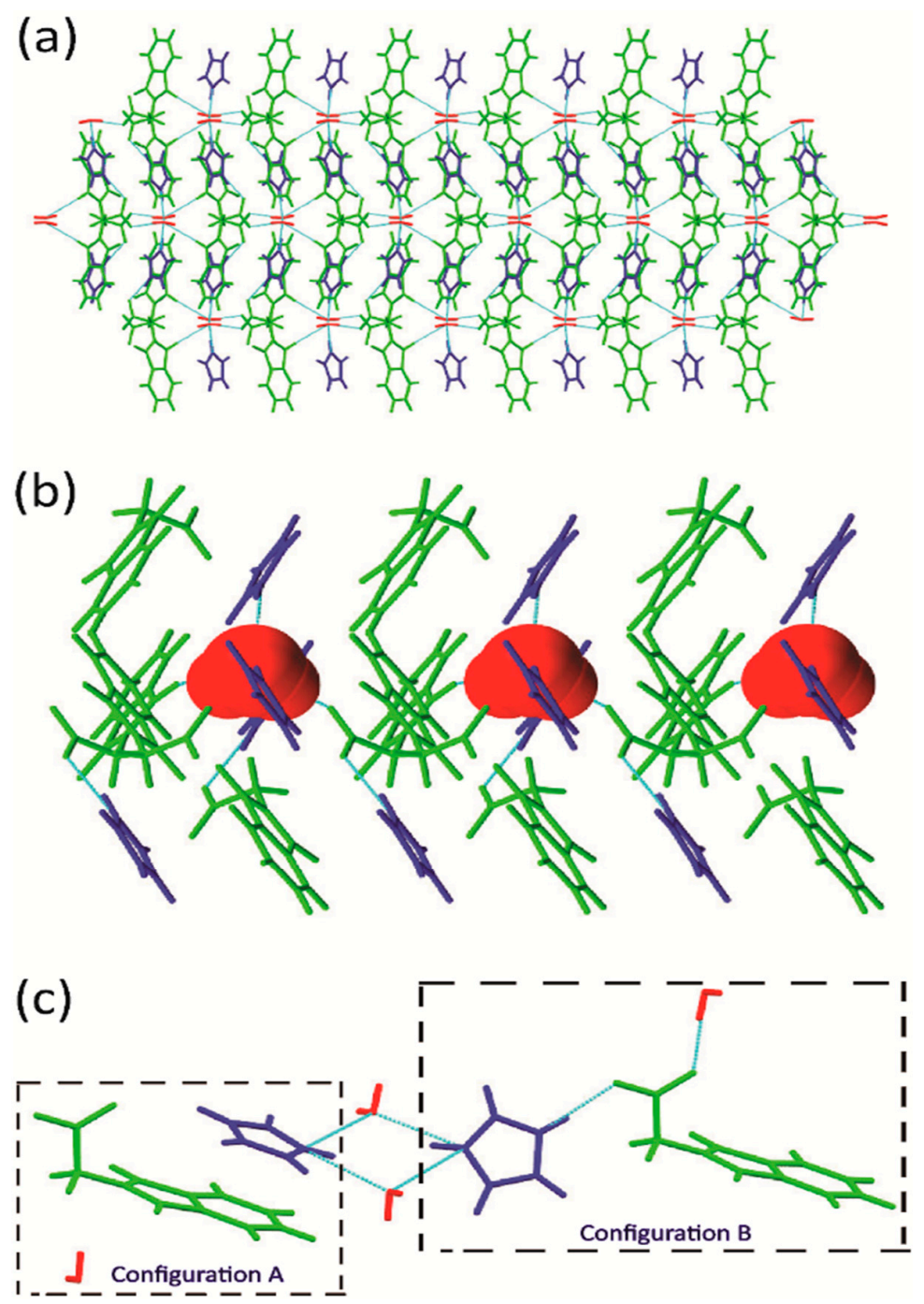

Figure 5. Supramolecular assembly of $\mathbf{I M}^{+}-\mathrm{NPG}^{-}-\mathrm{HYD}$ along different crystallographic axes (a) a-axis, (b) mixed stacking donor-acceptor columns connected to water through hydrogen bonds, and (c) configurations A and B crystallized within the framework of supramolecular assembly. 


\subsection{Hirshfeld Surface Analysis}

Hirshfeld surface analysis of charge transfer $\mathbf{I M}^{+}-\mathbf{N P G}^{-}-\mathbf{H Y D}$ gives useful information about the role of different intermolecular interactions in determining the optical and electronic properties. The Hirshfeld surface of $\mathrm{IM}^{+}$and $\mathrm{NPG}^{-}$separately presented in Figure S5 and plotted over a $\mathrm{d}_{\text {norm }}$ range from -1.138 to $0.880 \AA\left(\mathrm{IM}^{+}\right)$and -0.731 to $1.024 \AA\left(\mathrm{NPD}^{-}\right)$, shape index from -1.0 to $1.0 \AA$, and curvedness from -4.0 to $0.4 \AA$. All these three surfaces are transparently displayed to visualize $\mathbf{I M}^{+}-\mathbf{N P G}^{-}-\mathbf{H Y D}$ in an analogous orientation, around which they were mapped. We have taken the asymmetric unit among the entire unit cell from the single-crystal X-ray data. The information present in the hydrogen-bonding tables is corroborated adequately with the red spots, where the large rounded depressions (deep red) visible on the $\mathrm{d}_{\text {norm }}$ surface are indicative of the hydrogen-bonding interaction, and other visible spots are indicative of the $\mathrm{H} \cdots \mathrm{H}, \mathrm{C} \cdots \mathrm{C}, \mathrm{C} \cdots \mathrm{N}, \mathrm{C} \cdots \mathrm{H}, \mathrm{O} \cdots \mathrm{O}, \mathrm{O} \cdots \mathrm{N}$, and $\mathrm{C} \cdots \mathrm{O}$ interactions. The dominant $\mathrm{O} \cdots \mathrm{H}$ and $\mathrm{C} \cdots \mathrm{H}$ interactions can be viewed in the Hirshfeld surface map by the light red circular region in Figure S6a. These light red spots are the result of the $\mathrm{N} \cdots \mathrm{H}, \mathrm{C} \cdots \mathrm{O}$, $\mathrm{C} \cdots \mathrm{N}$, and $\mathrm{C} \cdots \mathrm{C}$ interactions. Other visible spots on the surface indicate $\mathrm{H} \cdots \mathrm{H}$ and further weaker and longer interactions apart from the hydrogen bonds. The presence of $\pi-\pi$ stacking interactions between the fused aromatic ring of $\mathrm{NPG}^{-}$moiety and the five-membered heteroaromatic ring of $\mathrm{IM}^{+}$moiety was reflected in the shape-index surface, as depicted in Figure S5b. As the inspection on the Hirshfeld surface show adjacent red and blue triangles on the shape-index surface, a characteristic feature is the presence of $\pi-\pi$ stacking interactions. Moreover, a clear flat region in the direction of the bottom of both sides of the $\mathrm{NPG}^{-}$and $\mathrm{IM}^{+}$moieties is evident on the curvedness surface, also depicting the presence of $\pi-\pi$ stacking interactions between these two moieties, as depicted in Figure S5c.

Furthermore, we have also presented two-dimensional (2D) fingerprint plots for each observed interaction between the atom pairs in the salt hydrate. The fingerprint plots can be decomposed to highlight particular atoms of pairwise interactions (Figure 6). This decomposition allows the parting of contributions from different types of interaction, which overlay the full fingerprint plot. Complementary regions are visible in the fingerprint plots, where one moiety acts as a donor (de $>$ di) and the other as an acceptor (de $<\mathrm{di}$ ). The $\mathrm{H} \cdots \mathrm{O} / \mathrm{O} \cdots \mathrm{H}$ intermolecular interactions appear as distinct spikes in the 2D fingerprint plot (see Figure 6). The $\mathrm{N} \cdots \mathrm{H}$ intermolecular interaction appears as two small broad spikes on in the 2D fingerprint plot. The proportion of $\mathrm{H} \cdots \mathrm{O} / \mathrm{O} \cdots \mathrm{H}$ interactions consists of $18.7 \%$ and $23.3 \%$ of the total Hirshfeld surface area. Such kind of dissimilar proportion for $\mathrm{O} \cdots \mathrm{H}$ interactions characterizes the oxygen of water interacting with the carbonyl oxygen $(\mathrm{C}=\mathrm{O})$ of the $\mathrm{NPG}^{-}$ moiety and is accountable for the building of the supramolecular self-assembly. A similar type of unequal proportions was also observed for $\mathrm{C} \cdots \mathrm{H}, \mathrm{C} \cdots \mathrm{N}, \mathrm{N} \cdots \mathrm{H}$, and $\mathrm{C} \cdots \mathrm{O}$ interactions, clearly indicating that these interactions participate in the growth of 3D supramolecular assembly of $\mathbf{I M}^{+}-\mathrm{NPG}^{-}-\mathbf{H Y D}$. 
(a)
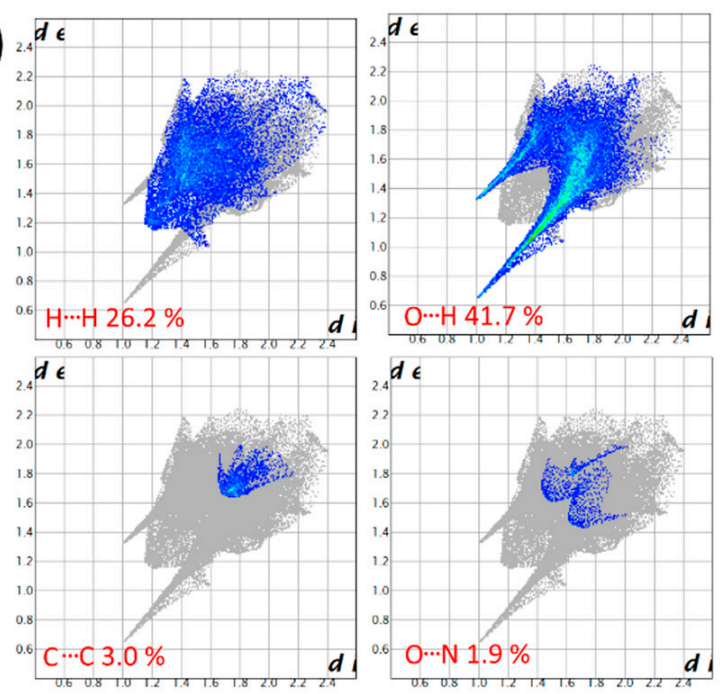

d.
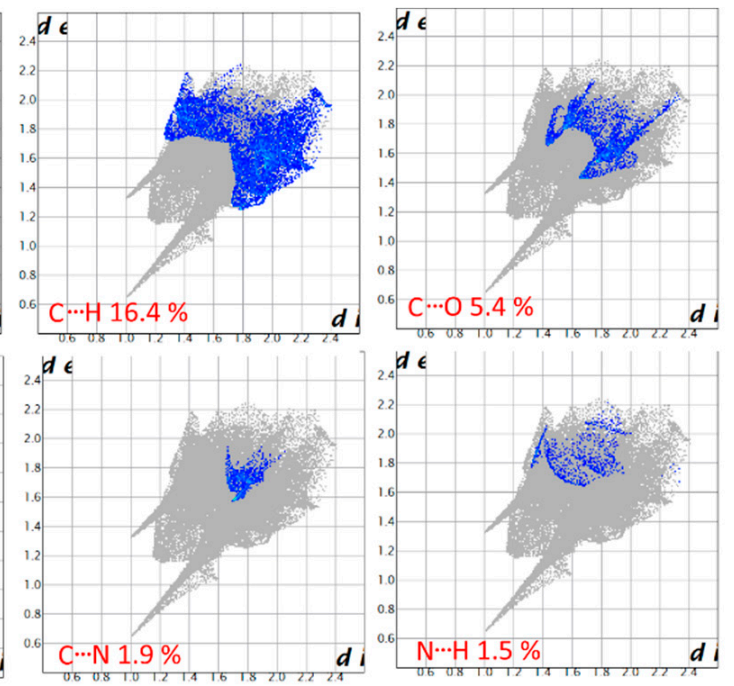

(b)
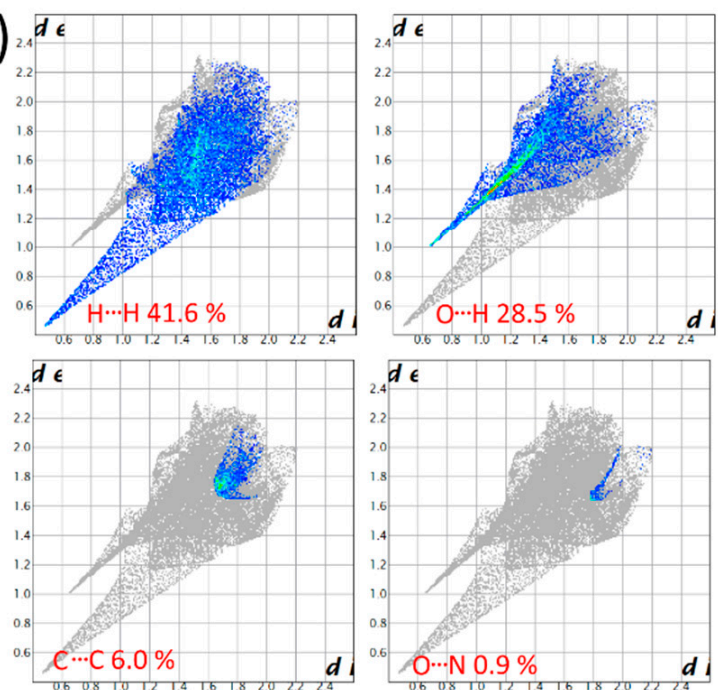
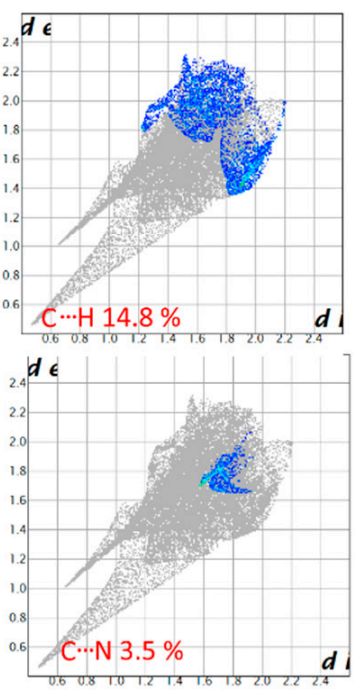
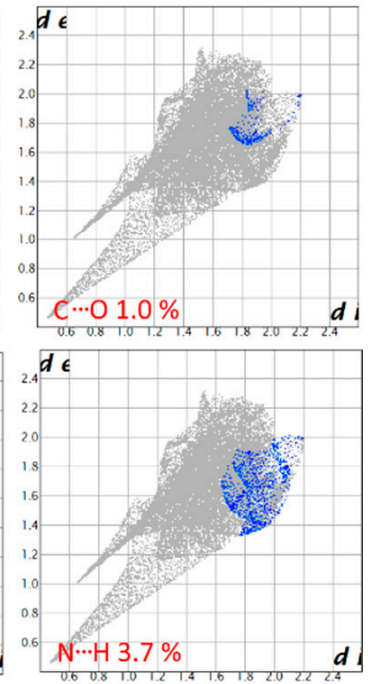

Figure 6. Fingerprint plots of cation and anion of $\mathbf{I M}^{+}-\mathrm{NPG}^{-}-\mathrm{HYD},(\mathbf{a}) \mathrm{IM}^{+}$, and (b) $\mathrm{NPG}^{-}$: full (upper left) and resolved into different intermolecular interactions showing the percentages of interactions contributing to the total Hirshfeld surface area of the cation and anion in the salt hydrate. The $x$-axis and $y$-axis represent the values of $d_{e}$ (distance from the point to the nearest nucleus external to the surface) and $d_{i}$ (distance to the nearest nucleus internal to the surface).

\subsection{Quantum-Theory-of-Atoms-in-Molecules Analysis}

The topology of calculated electron density at the DFT/M062X/cc-pVTZ level of theory has been analyzed by employing the QTAIM approach. The quantum theory of atoms-in-molecules (QTAIM) has proved to be a great tool for investigating a variety of chemical interactions. According to the QTAIM, which was developed by Bader, a chemical bond is distinctively described by a line of maximum electron density linking two bonded atoms (bond path, BP) on which a bond critical point (BCP) $(3,-1)$ is present $[49,50]$. Koch and Popelier [51] quantified that a hydrogen bond would be present in a molecular structure if the electron density is within the range of 0.002-0.040 atomic unit (a.u.), and the resultant Laplacian within the range of $0.024-0.139$ a.u. The presence of hydrogen bonds was further supported by Rozas et al. According to Rozas et al. [52,53], these hydrogen-bond interactions may be categorized as follows: (i) strong and covalent hydrogen bond, when $\left(\nabla^{2} \rho\right)<0$ and $\mathrm{H}<0$; (ii) medium and partially covalent hydrogen bond, when $\left(\nabla^{2} \rho\right)>0$ and $\mathrm{H}<0$; and (iii) weak and typically electrostatic hydrogen bond, when $\left(\nabla^{2} \rho\right)>0$ and $\mathrm{H}>0$. 
In configuration $\mathrm{A}, \mathrm{BCPs}$ and $\mathrm{BPs}$ are observed between $\mathrm{NPG}^{-}$and $\mathrm{IM}^{+}$moieties (Figure 7a), indicating that both the moieties are linked through weak interactions, viz. N22 (IM $\left.{ }^{+}\right) \cdots \mathrm{C}^{-} \mathrm{C} 11\left(\mathrm{NPG}^{-}\right)$ and $\mathrm{C} 25\left(\mathrm{IM}^{+}\right) \cdots \mathrm{C} 11\left(\mathrm{NPG}^{-}\right)$and also through $\pi-\pi$ stacking interaction, which was confirmed from the NCI studies (see Figure S7). Furthermore, the NPG- moiety is linked to HYD via weak O2 $\left(\mathrm{NPG}^{-}\right)$).O32 (HYD) interaction. While configuration B is stabilized through strong interactions, namely,

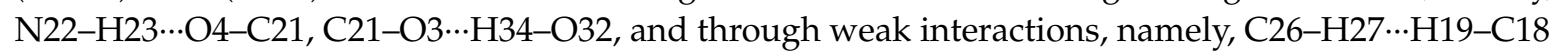
(Figure 7b).
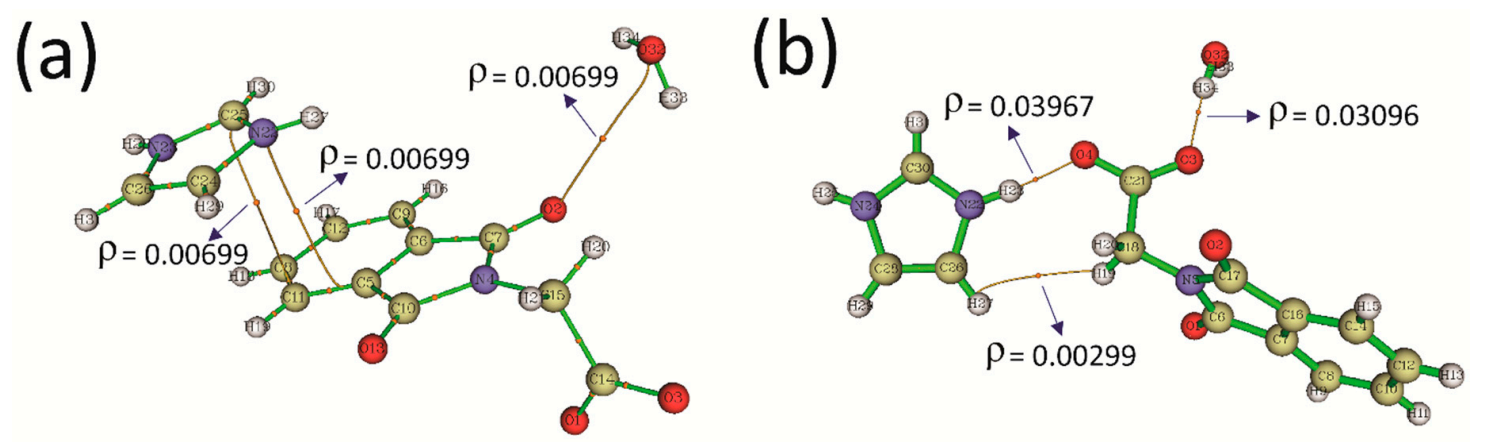

Figure 7. QTAIM-analysis-based molecular graph of two different configurations of $\mathbf{I M}^{+}-\mathrm{NPG}^{-}-\mathrm{HYD}_{\text {: }}$ (a) A and (b) B, both showing the BP and electron density ( $\rho$ ) computed at bond critical points (BCPs). Orange circles indicate the BCPs.

The atomic basins of the contour-line map of the electron-density gradient, as well as its Laplacian distribution $\nabla^{2} \rho(\mathrm{r})$, BCPs $(3,-1)$, BPs, selected zero-flux surfaces, electron-localization function (ELF), and contour-line electrostatic-potential map for the above-described atoms of pairwise interactions are depicted in Figure 8. Table 4 presents the topological properties at the selected BCPs of $\mathbf{I M}^{+}-\mathbf{N P G}^{-}-\mathbf{H Y D}$. The strengths of the observed noncovalent interactions were also determined using the methods developed by Espinosa [54] et al. and Vener [55] et al. Additionally, the disproportion in the electron-density distribution between $\mathrm{IM}^{+}, \mathrm{NPG}^{-}$, and $\mathrm{H}_{2} \mathrm{O}$ can be noticeably understood from the 2D-ELF map of $\mathbf{I M}^{+}-\mathbf{N P G}^{-}-\mathbf{H Y D}$ presented in Figure 8c, with a color scale (in a.u.) on the right-hand side of the plot.

Table 4. Topological parameters of electron density: electron density $(\rho(\mathrm{r}))$, electron-density Laplacian distribution $\left(\nabla^{2} \rho(\mathrm{r})\right)$, potential-energy density $(V(\mathrm{r}))$, kinetic-energy density $(G(\mathrm{r}))$, and electronic-energy density $(H(r))$ at the BCPs $(3,-1)$, corresponding to the non-covalent interactions in $\mathbf{I M}^{+}-\mathbf{N P G}^{-}-\mathbf{H Y D}$, as well as the energies for these interactions $\left(\mathrm{E}_{\mathrm{int}}(\mathrm{kcal} / \mathrm{mol})\right)$, defined by two approaches. Parameters all in a.u.

\begin{tabular}{|c|c|c|c|c|c|c|c|}
\hline $\mathrm{IM}^{+}-\mathrm{NPG}^{-}-\mathrm{HYD}$ & $\rho(\mathbf{r})$ & $\nabla^{2} \rho(\mathrm{r})$ & $V(\mathbf{r})$ & $G(\mathrm{r})$ & $H(\mathbf{r})$ & $\mathrm{E}_{\text {int }}{ }^{\mathrm{a}}$ & $E_{\text {int }}^{b}$ \\
\hline \multicolumn{8}{|c|}{ Configuration A } \\
\hline$N 22 \cdots C 5-C 11$ & 0.00699 & 0.02326 & -0.00311 & 0.00446 & 0.00135 & 0.9757 & 1.2006 \\
\hline 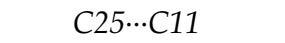 & 0.00654 & 0.02020 & -0.00316 & 0.00410 & 0.00094 & 0.9914 & 1.1037 \\
\hline $\mathrm{O} 2 \cdots O 32$ & 0.00404 & 0.01502 & -0.00241 & 0.00308 & 0.00067 & 0.7561 & 0.8291 \\
\hline \multicolumn{8}{|c|}{ Configuration B } \\
\hline 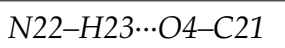 & 0.03967 & 0.12031 & -0.03865 & 0.03436 & -0.00428 & 12.1266 & 9.2497 \\
\hline 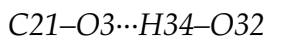 & 0.03096 & 0.11224 & -0.02988 & 0.02897 & -0.00091 & 9.3749 & 7.7987 \\
\hline 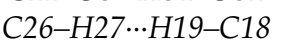 & 0.00299 & 0.01240 & -0.00149 & 0.00229 & 0.00080 & 0.4674 & 0.6164 \\
\hline
\end{tabular}


(a)
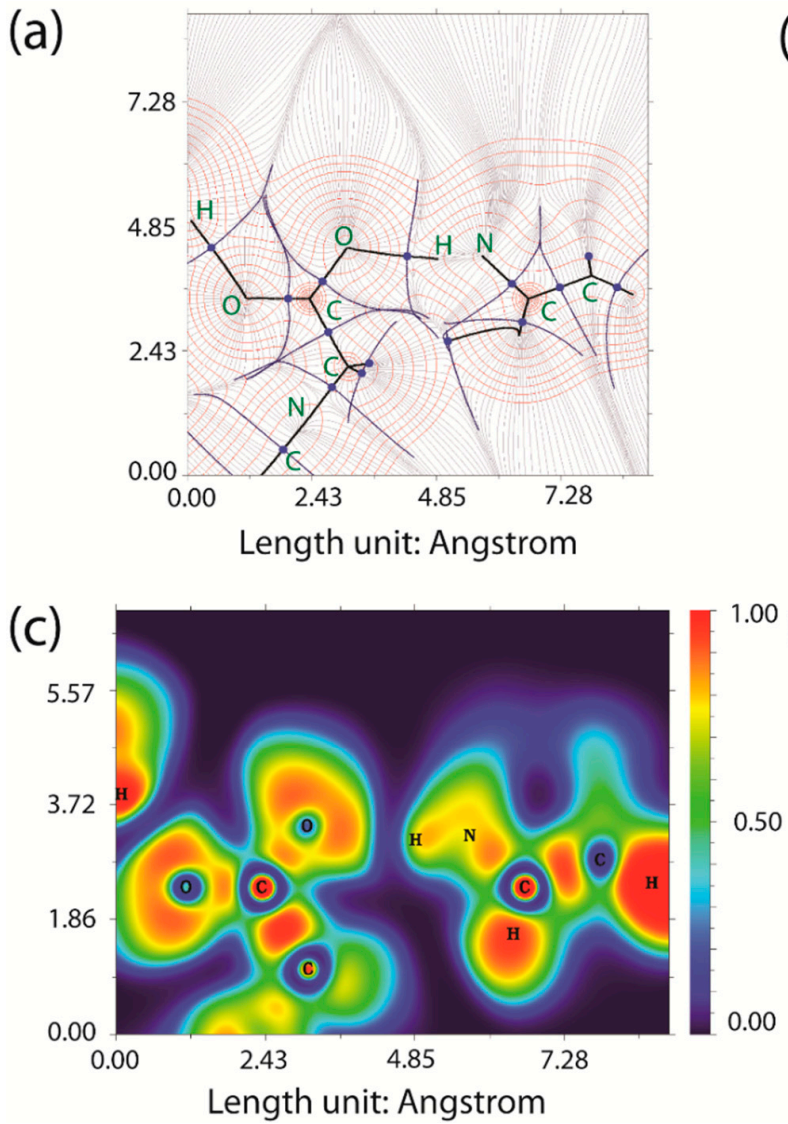

(b)
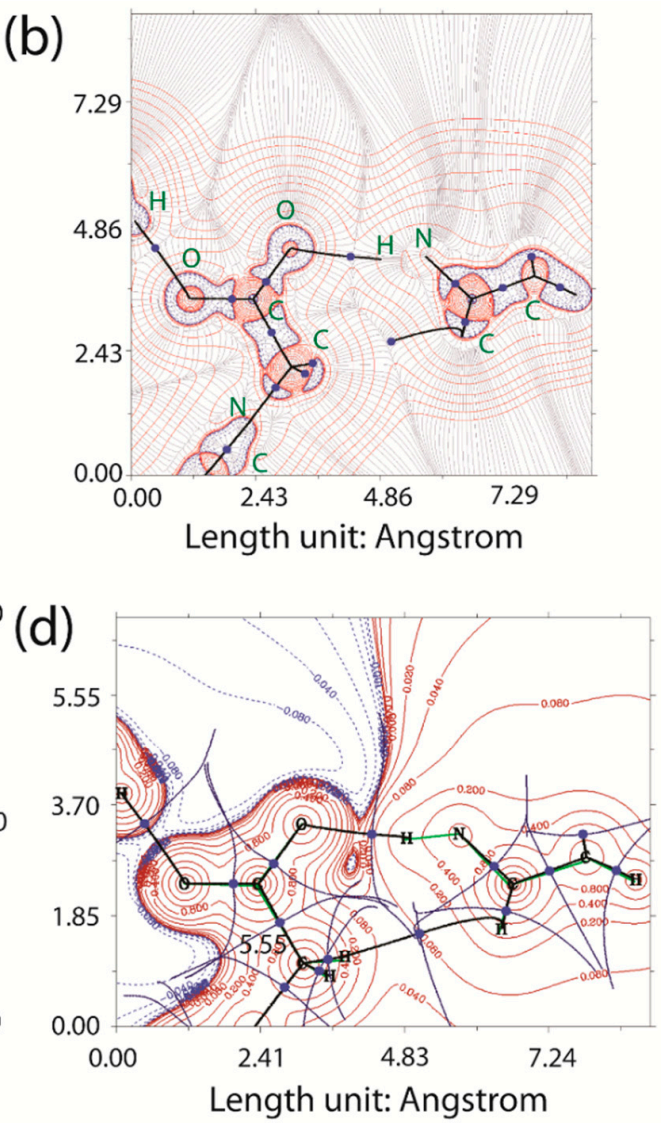

Figure 8. QTAIM analysis of charge-assisted hydrogen-bonding interactions in $\mathbf{I M}^{\mathbf{+}}-\mathbf{N P G}^{-}-\mathbf{H Y D}$ (for configuration A). (a) Contour-line plots of the electron density $\rho$. (b) Contour-line plots of the Laplacian distribution of electron density $\nabla^{2} \rho(\mathrm{r})$, where the solid (red) and dashed (blue) lines correspond to the positive and negative values of $\nabla^{2} \rho(\mathrm{r})$, respectively. (c) Surface maps of ELF. (d) Counter-line map of the electrostatic surface potential (ESP), where the solid (red) and dashed (blue) lines correspond to the positive and negative values of ESP, respectively. BPs are shown as black lines, the selected zero-flux surfaces, or interbasin paths as blue lines, and BCPs $(3,-1)$ are shown in blue.

\section{5. $C T$ in $I M^{+}-N P G^{-}-H Y D$}

The DFT calculations have been performed to investigate the electronic properties of the supramolecular $\mathbf{I M}^{+}-\mathbf{N P G}^{-}-\mathbf{H Y D}$ salt hydrate. In configuration $\mathbf{A}$, the total Hirshfeld charges (atomic dipole moment corrected, $\mathrm{ADC}$ ) for $\mathrm{NPG}^{-}, \mathrm{IM}^{+}$, and HYD fragments were calculated to be -0.921934 (-0.841933), $0.939092(0.939091)$, and $-0.017215(-0.017215)$, respectively. While in configuration $\mathbf{B}$, the Hirshfeld charges for $\mathrm{NPG}^{-}, \mathrm{IM}^{+}$, and HYD fragments were calculated to be $-0.675391,0.804130$, and -0.128862 , respectively. The atom wise Hireshfeld and atomic dipole moment corrected (ADC) charges are given in Table S3. Additionally, the static dipole moments of 13.284517 and 7.289192 a.u., with the vector pointing from $\mathrm{NPG}^{-}$to $\mathrm{IM}^{+}$fragment, in configurations $\mathbf{A}$ and $\mathbf{B}$, respectively, confirm the $\mathrm{CT}$ from $\mathrm{NPG}^{-}$to $\mathrm{IM}^{+}$(Figure S8) [48]. The interfragmentary CTs were further confirmed by the analysis of the frontier molecular orbitals (FMOs), i.e., HOMO and LUMO, of $\mathbf{I M}^{+}-\mathbf{N P G}^{-}-\mathbf{H Y D}$ (see Figure 9). Furthermore, as a result of the intermolecular hydrogen bonds and $\pi-\pi$ stacking in the ground state of this donor-acceptor salt hydrate, the CT process occurs from HOMO to LUMO, because of which the electron cloud reorganizes over the donor-acceptor moieties, thereby forming new molecular orbitals (MOs) [56]. Consequently, the electronic transitions occur between these newly formed MOs from the ground state to the excited CT states. Both HOMO and LUMO are symmetrically and spatially localized on $\mathrm{NPG}^{-}$(donor) and $\mathrm{IM}^{+}$(acceptor), respectively. The effective spatial separation between HOMO and 
LUMO, coupled with a small $\triangle \mathrm{E}_{\mathrm{HOMO}}$-LUMO as compared to individual NPG and IM, facilitates the induction of anion-to-cation $\mathrm{CT}$ in $\mathbf{I M}^{+}-\mathbf{N P G}^{-}-\mathbf{H Y D}$, through space.
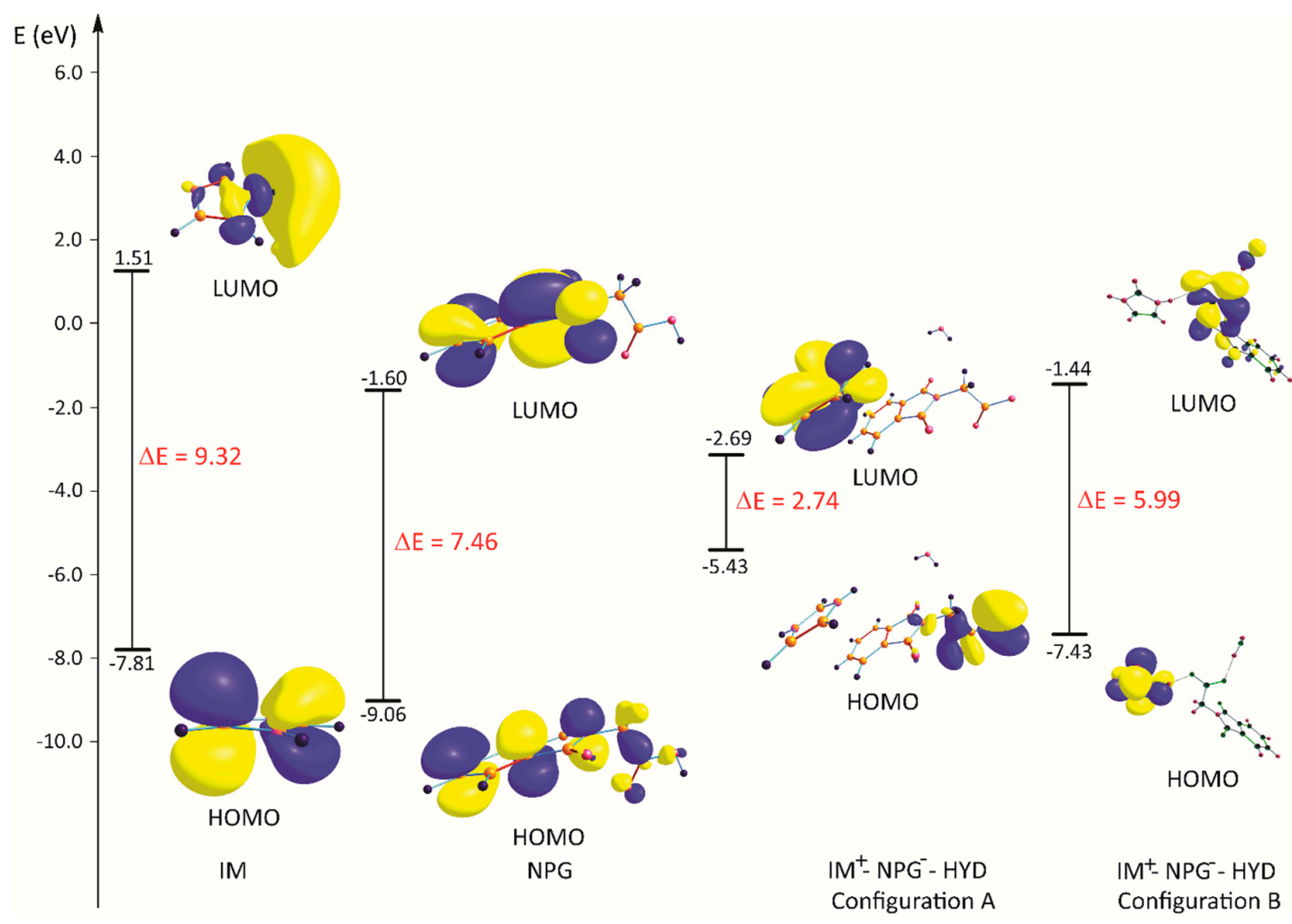

Figure 9. Energy diagrams and Kohn-Sham orbitals of IM, NPG, and $\mathbf{I M}^{+}-\mathrm{NPG}^{-}-\mathbf{H Y D}$ (configurations A and $\mathbf{B})$. The value of contour envelopes is 0.03 a.u.

The time-dependent density functional theory (TD-DFT) based calculations were performed to determine the oscillator strengths $(f)$ and the corresponding energies of the vertical transitions for $\mathrm{IM}^{+}-\mathrm{NPG}^{-}-\mathbf{H Y D}$, and the major MOs contributing toward the electronic transitions are presented in Table S3. Therefore, the 20 excited states were calculated for $\mathbf{I M}^{+}-\mathbf{N P G}^{-}-\mathbf{H Y D}$ using a closed-shell procedure at CAM-B3LYP/cc-pVTZ level and, as discussed hereafter. The calculated absorption spectrum for $\mathbf{I M}^{\mathbf{+}}-\mathbf{N P G}^{-}-\mathbf{H Y D}$ is depicted in Figure 1. The calculated spectrum reproduces the major spectral features and is in good agreement with the experimental absorption spectrum. The strongest absorption band, which is centered at $300 \mathrm{~nm}$ in the experiment, is also reproduced in the TD-DFT calculation which is mainly the results of HOMO-2 to LUMO+4 transitions from the singlet ground state to the 10th singlet excited state (S0-S10). Other transitions having low oscillator strengths are also observed in the calculated spectrum in this absorption region, which is presented in Table S4. By analyzing the FMOs responsible for these transitions, it is indicated that the character of this band corresponds primarily to $\pi-\pi^{*}$ transition. The other broadband with weak absorption appeared in the higher wavelength region (350-550 nm); this broadband was absent from the free IM and NPG absorption spectra and was reproduced in the TD-DFT calculation, which mainly involves multiple superimposed absorptions from the singlet ground state (S0) to the singlet excited states (Sn, where $n=1-4)$ with similar oscillator strengths, comprising the donor ( $\left.\mathrm{NPG}^{-}\right)$-acceptor $\left(\mathrm{IM}^{+}\right) \mathrm{CT}$ transitions. Interestingly, the FMOs involved in these electronic transitions were localized mostly on either the donor or acceptor moieties, resulting in an effective CT [57]. When an electronic excitation occurs, we supposed that the charge density transferred from the donor to acceptor. The excitation can be attributed mainly to the transitions of the MOs from HOMOs to LUMOs. Nevertheless, this model of single orbital pair is not appropriate in most practical cases, and this analysis considers the $\mathbf{I M}^{+}-\mathrm{NPG}^{-}-\mathbf{H Y D}$ transition processes to comprise the contributions of multiple pairs of MOs, and charge-density transfers are considered as electrons and holes 
in the resulting text. The distribution isosurfaces of electron and hole for $\mathbf{I M}^{+}-\mathbf{N P G}^{-}-\mathbf{H Y D}$ is depicted in Figures S9 and S10. Spatially distributed electrons and a hole in a particular excitation correspond to CT excitation, while alternatively or merged distribution of the electron and hole represents local excitation [58]. Hence, in $\mathbf{I M}^{+}-\mathrm{NPG}^{-}-\mathbf{H Y D}$, mostly electrons and holes are spatially distributed at $\mathrm{IM}^{+}$ and NPG $^{-}$fragments, respectively, indicating that both the absorption bands at 300 and $350-550 \mathrm{~nm}$ possess a CT character. Additionally, we have also calculated the extent of interfragmentary CT and charge-density difference (CDD) from the donor $\left(\mathrm{NPG}^{-}\right)$to acceptor $\left(\mathrm{IM}^{+}\right)$fragment, as depicted in Figure 10. Hence, these theoretical results are in good agreement with the experimental results, and it can be concluded that $\mathbf{I M}^{+}-\mathbf{N P G}^{-}-\mathbf{H Y D}$ behaves as a CT salt hydrate.
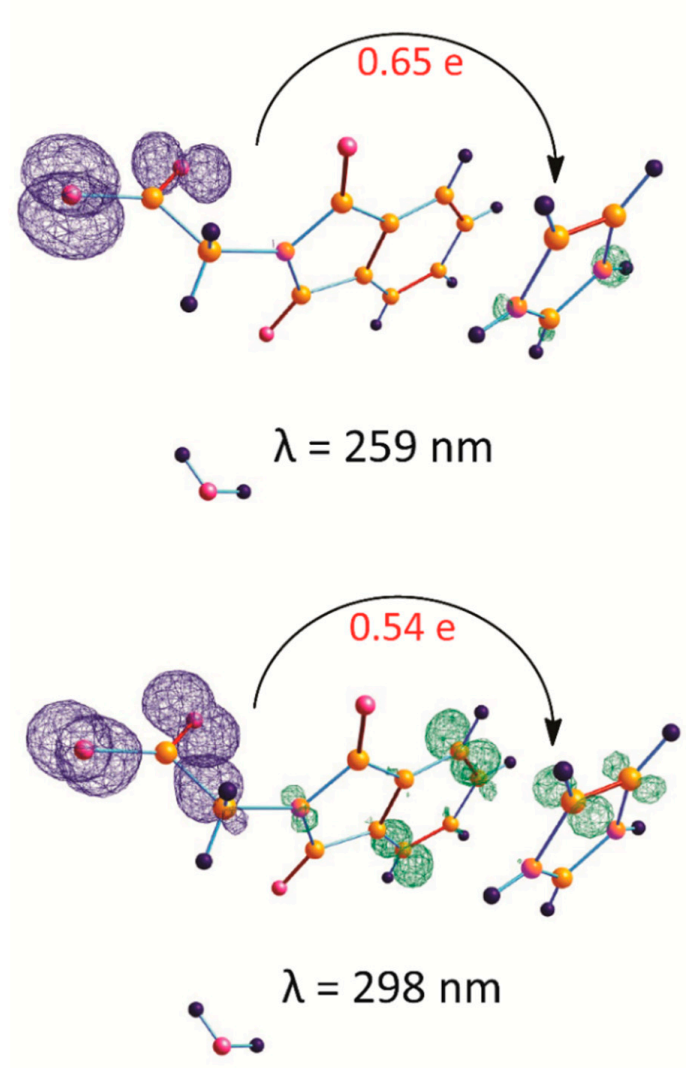
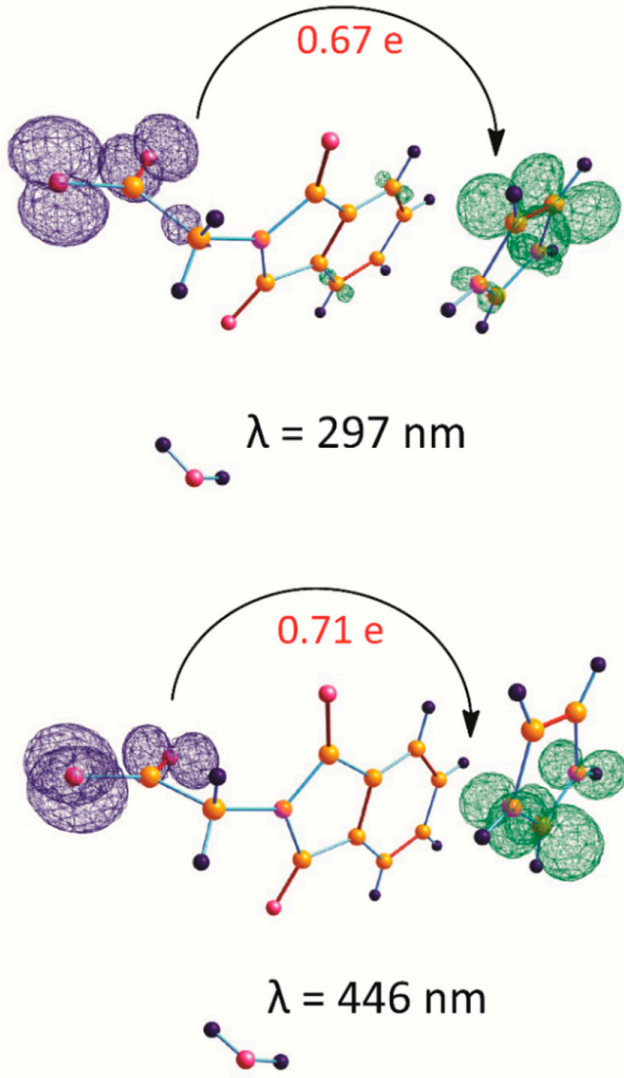

Figure 10. CDD and the extent of inter-fragment $\mathrm{CT}$ between the excited state and the ground state of IM $^{+}-$NPG $^{-}-$HYD for the absorptions at 259, 297, 298, and $446 \mathrm{~nm}$. Blue and green surfaces represent the accumulation and diminution of charge concentration during excitation. The value of contour envelopes is 0.002 a.u.

\subsection{Natural Bond Orbital Analysis}

The NBO analysis was carried out to investigate the role of charge transfer in the charge-assisted hydrogen bond and $\pi \cdots \pi$ stacking interaction using the second-order perturbation theory of the Fock matrix within the framework of natural bond orbital (NBO) analysis. From the NBO analysis, the strength of the CT donor-acceptor interactions between $\mathrm{NPG}^{-}$and $\mathrm{IM}^{+}$or $\mathrm{H}_{2} \mathrm{O}$ in $\mathbf{I M}^{+}-\mathrm{NPG}^{-}-\mathbf{H Y D}$ can be obtained by probing the interactions between the filled ( $i$, donor) Lewis-type NBOs and empty $(j$, acceptor) non-Lewis-type NBOs. In configuration A, both the $\mathrm{NPG}^{-}$and $\mathrm{IM}^{+}$fragments behave as a donor and also as an acceptor. In addition, the charge transferred from the donor: $\mathrm{NPG}^{-}$to the acceptor: $\mathrm{IM}^{+}$and vice versa

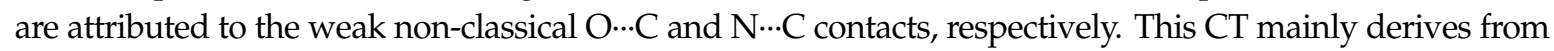
the lone electron pairs of both oxygen and nitrogen in $\mathrm{NPG}^{-}$and $\mathrm{IM}^{+}$, respectively, along with the empty antibonding orbitals of the carbon of the acceptor fragment. The energies of these interactions $\mathrm{E}(2) \mathrm{and}$ donor-acceptor NBO orbital pairs are presented in Table 5 and Figures 11 and 12. Such behavior indicates 
that the charge facilitates the whole supramolecular assembly along the crystallographic molecular axis. While in configuration $\mathrm{B}$, the $\mathrm{CT}$ resulting from the charge-assisted hydrogen bond is mainly attributed to the electron-donor $\left(\mathrm{NPG}^{-}\right)$and electron-acceptor $\left(\mathrm{IM}^{+}\right)$interactions of the lone pair electrons of oxygen (from the carboxylate group) of $\mathrm{NPG}^{-}$with an empty antibonding orbitals of the hydrogen-bonding donor hydrogen atom of $\mathrm{IM}^{+} \mathrm{LP}(\mathrm{O})$ to $\mathrm{BD}^{*}(\mathrm{D}-\mathrm{H})$.
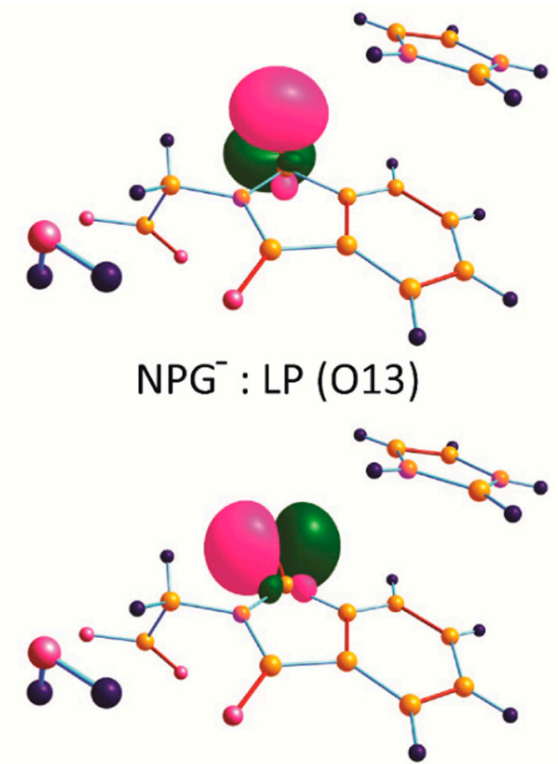

$N^{\prime} G^{-}:$LP (O13)

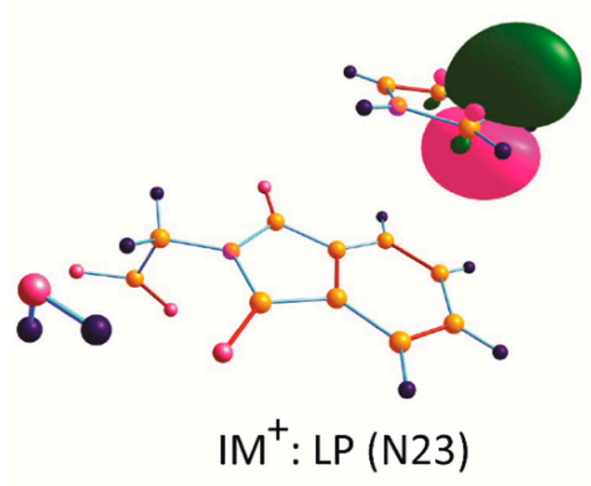

Donor
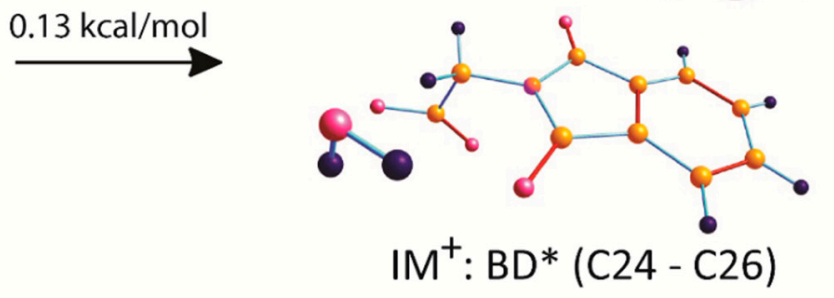

$0.22 \mathrm{kcal} / \mathrm{mol}$
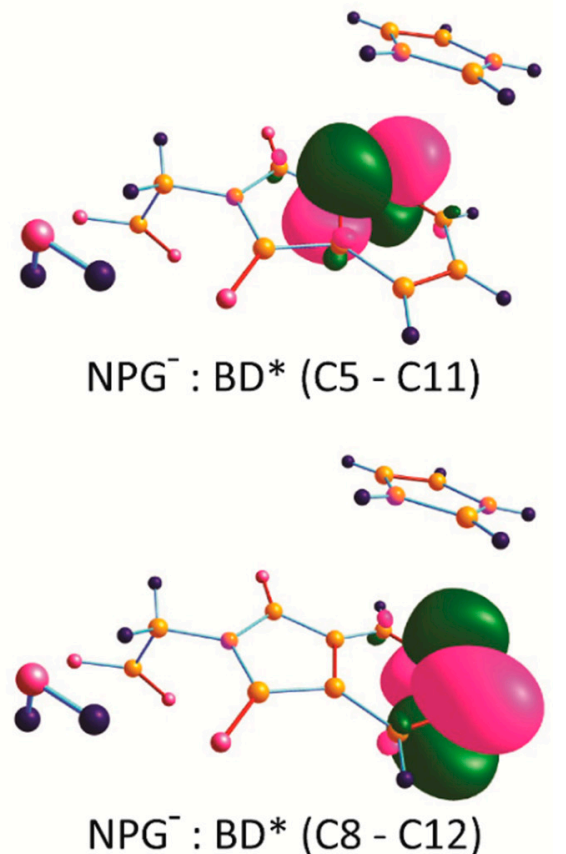

Acceptor

Figure 11. $\mathrm{LP} \rightarrow \mathrm{BD}^{*}$ donor-acceptor orbitals' interaction derived from the NBO analysis of $\mathrm{IM}^{+}-\mathrm{NPG}^{-}-\mathbf{H Y D}$ (for configuration A). Hydrogen atoms are omitted for clarity (isovalue $=0.03$ ). 

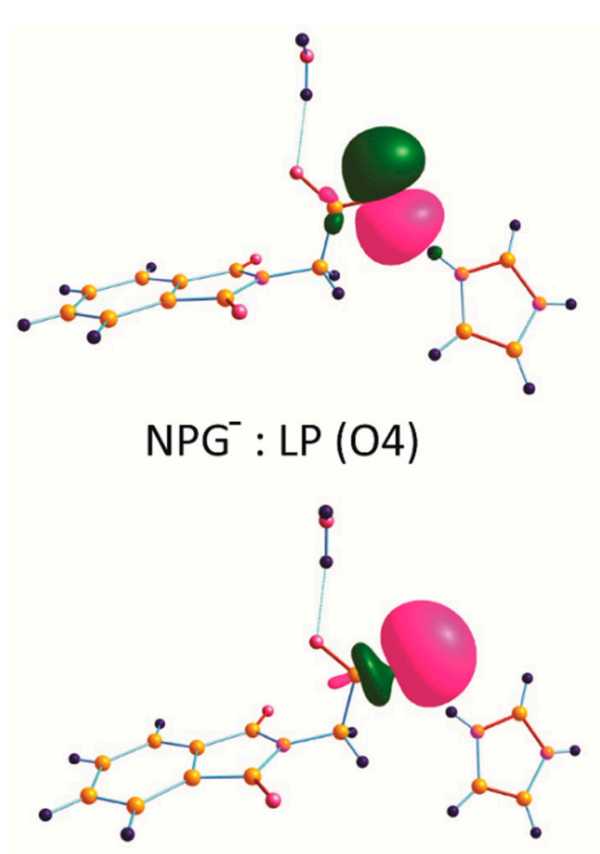

$18.08 \mathrm{kcal} / \mathrm{mol}$

$\mathrm{NPG}^{-}$: LP (04)

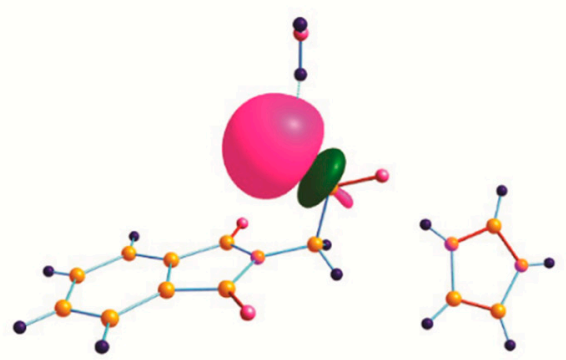

$9.73 \mathrm{kcal} / \mathrm{mol}$

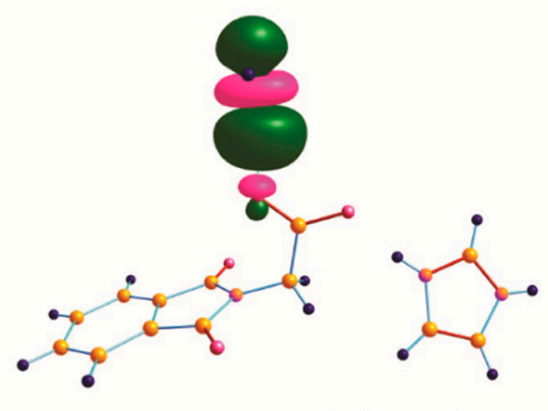

HYD : BD* (O32)

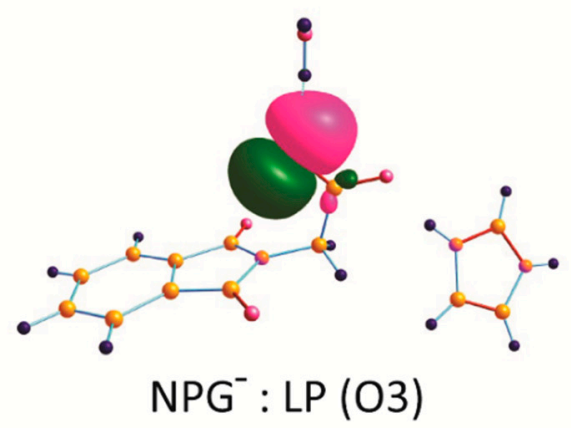

Donor

\section{Acceptor}

Figure 12. $\mathrm{LP} \rightarrow \mathrm{BD}^{*}$ donor-acceptor orbitals' interaction derived from the $\mathrm{NBO}$ analysis of $\mathbf{I M}^{+}-\mathbf{N P G}^{-}-\mathbf{H Y D}$ (for configuration A). Hydrogen atoms are omitted for clarity (isovalue $=0.03$ ). 
Table 5. Results of NBO analysis of donor-acceptor interaction in $\mathbf{I M}^{+}-\mathrm{NPG}^{-}-\mathbf{H Y D}$, determined using the second-order perturbation theory.

\begin{tabular}{|c|c|c|}
\hline Donor NBO (i) & Acceptor NBO (j) & E (2) kcal/mol \\
\hline \multicolumn{3}{|c|}{ Configuration A } \\
\hline $\mathrm{IM}^{+}: \mathrm{LP}(\mathrm{N} 23)$ & $\mathrm{NPG}^{-}: \mathrm{BD}^{*}(\mathrm{C} 5-\mathrm{C} 11)$ & 0.07 \\
\hline $\mathrm{IM}^{+}: \mathrm{LP}(\mathrm{N} 23)$ & $\mathrm{NPG}^{-}: \mathrm{BD}^{*}(\mathrm{C} 8-\mathrm{C} 12)$ & 0.15 \\
\hline $\mathrm{NPG}^{-}: \mathrm{LP}(\mathrm{O} 13)$ & $\mathrm{IM}^{+}: \mathrm{BD}^{*}(\mathrm{C} 24-\mathrm{C} 26)$ & 0.05 \\
\hline $\mathrm{NPG}^{-}: \mathrm{LP}(\mathrm{O} 13)$ & $\mathrm{IM}^{+}: \mathrm{BD}^{*}(\mathrm{C} 24-\mathrm{C} 26)$ & 0.08 \\
\hline \multicolumn{3}{|c|}{ Configuration B } \\
\hline $\mathrm{NPG}^{-}: \mathrm{LP}(\mathrm{O} 4)$ & $\mathrm{IM}^{+}: \mathrm{BD}^{*}(\mathrm{~N} 22-\mathrm{H} 23)$ & 4.03 \\
\hline $\mathrm{NPG}^{-}: \mathrm{LP}(\mathrm{O} 4)$ & $\mathrm{IM}^{+}: \mathrm{BD}^{*}(\mathrm{~N} 22-\mathrm{C} 26)$ & 0.21 \\
\hline $\mathrm{NPG}^{-}: \mathrm{LP}(\mathrm{O} 4)$ & $\mathrm{IM}^{+}: \mathrm{BD}^{*}(\mathrm{~N} 22-\mathrm{H} 23)$ & 14.05 \\
\hline $\mathrm{NPG}^{-}: \mathrm{LP}(\mathrm{O} 4)$ & $\mathrm{IM}^{+}: \mathrm{BD}^{*}(\mathrm{~N} 22-\mathrm{C} 26)$ & 0.23 \\
\hline $\mathrm{NPG}^{-}: \mathrm{LP}(\mathrm{O} 4)$ & $\mathrm{IM}^{+}: \mathrm{BD}^{*}(\mathrm{~N} 22-\mathrm{C} 30)$ & 0.20 \\
\hline $\mathrm{NPG}^{-}: \mathrm{LP}(\mathrm{O} 4)$ & $\mathrm{IM}^{+}: \mathrm{BD}^{*}(\mathrm{~N} 22-\mathrm{C} 30)$ & 0.05 \\
\hline $\mathrm{NPG}^{-}: \mathrm{LP}(\mathrm{O} 4)$ & $\mathrm{IM}^{+}: \mathrm{BD}^{*}(\mathrm{~N} 22-\mathrm{H} 23)$ & 0.11 \\
\hline $\mathrm{NPG}^{-}: \mathrm{LP}(\mathrm{O} 4)$ & $\mathrm{IM}^{+}: \mathrm{BD}^{*}(\mathrm{~N} 22-\mathrm{C} 30)$ & 0.31 \\
\hline $\mathrm{NPG}^{-}: \mathrm{LP}(\mathrm{O} 3)$ & HYD: BD* (O32-H34) & 3.04 \\
\hline $\mathrm{NPG}^{-}:$LP (O3) & HYD: BD* (O32-H34) & 6.69 \\
\hline
\end{tabular}

\section{Conclusions}

An organic supramolecular salt hydrate (imidazolium:N-phthalolylglycinate: $\mathrm{H}_{2} \mathrm{O} ; \mathbf{I M}^{+}-\mathbf{N P G}^{-}-\mathbf{H Y D}$ ) has been synthesized and characterized by single X-ray crystallography, ${ }^{1} \mathrm{H}$ NMR, IR, tandem mass-spectroscopy (ESI-MS/MS), elemental analysis, and UV-vis spectroscopy. The $\mathbf{I M}^{+}-\mathrm{NPG}^{-}-\mathbf{H Y D}$ crystallizes in the monoclinic space group $\mathrm{C} 2 / \mathrm{c}(Z=8)$. The $\mathbf{I M}^{+}-\mathrm{NPG}^{-}-\mathbf{H Y D}$ salt hydrate was formed via supramolecular self-assembly. The mixed $\pi-\pi$ stacking donor-acceptor interactions and charge-assisted hydrogen-bonding interactions between $\mathrm{IM}^{+}$and $\mathrm{NPG}^{-}$are the primary driving intermolecular interactions for the self-assembly, and they contribute to the CT characteristics of $\mathbf{I M}^{+}-\mathbf{N P G}^{-}-\mathbf{H Y D}$. The nature of the anion-to-cation CT was confirmed by comparing UV-vis spectra of IM and NPG, new absorption broadband ranging from 350 to $550 \mathrm{~nm}$ has appeared in $\mathbf{I M}^{+}-$NPG $^{-}-\mathbf{H Y D}$, corresponds to the CT band, confirms the formation of donor-acceptor CT IM+ ${ }^{+}-\mathrm{NPG}^{-}-\mathbf{H Y D}$.

A series of DFT calculations have been performed to reproducing the experimental results. The DFT calculated structures and ${ }^{1} \mathrm{H}$ NMR spectrum are in good agreement with experimental results. The TDDFT calculated UV-vis spectrum reproduced major spectral features observed in the experimentally recorded spectrum. Also, electron-hole and Hirshfeld charge analysis validated the charge transfer (CT) nature of salt hydrate. Furthermore, the Hirshfeld surface, QTAIM, and NBO analysis explored the nature and strength of non-covalent interaction and their role in the charge transfer phenomenon.

\section{Experimental Section}

\subsection{General Methods and Instrumentation}

All the starting materials were purchased from well-known chemical suppliers (Sigma-Aldrich St. Louis, MO, USA) and were used without further purification. The solvents used were of analytical or chromatographic grade.

The infrared spectra were obtained (KBr disk, 400-4000 $\mathrm{cm}^{-1}$ ) on a Perkin-Elmer Model 1320 spectrometer (Waltham, MA, USA). The electronic spectrum was recorded on PerkinElmer UV-vis spectrophotometer (Waltham, MA, USA). The NMR spectra were obtained on a Bruker DRX-400 spectrometer (Billerica, MA, USA) with $\mathrm{Me}_{2} \mathrm{SO}-d_{6}$ as the solvent. 


\subsection{Synthesis of $I M^{+}-N P G^{-}-H Y D(1: 1: 1)$}

A total of $333 \mathrm{mg}$ ( $2 \mathrm{mmol})$ of NPG and $104 \mathrm{mg}(2.0 \mathrm{mmol})$ of IM were milled with 5-10 drops of aqueous methanolic solution for $30 \mathrm{~min}$ at room temperature, and salt formation was confirmed using the IR, NMR, and ESI techniques. Then, the compound (50 mg) was dissolved in an aqueous solution of methanol and left to evaporate slowly at room temperature. Good-quality crystals suitable for single-crystal X-ray crystallography analysis were obtained after 15 days.

M.p. $154^{\circ} \mathrm{C}$. Anal. cal. for $\mathrm{C}_{13} \mathrm{H}_{13} \mathrm{~N}_{3} \mathrm{O}_{5}$ (\%): C, 53.61; $\mathrm{H}, 4.50 ; \mathrm{N}, 14.43$. Anal. found: $\mathrm{C}, 53.65 ; \mathrm{H}$, 4.58; N, 14.44. FT IR (KBr, $\left.v_{\max } / \mathrm{cm}^{-1}\right): 3310 v(\mathrm{OH}) ; 3173 v(\mathrm{~N}-\mathrm{H}) ; 2934 v\left(-\mathrm{CH}_{2}\right) ; 1708 v_{\text {asym }}\left(\mathrm{COO}^{-}\right)$; $1420 v_{\text {sym }}\left(\mathrm{COO}^{-}\right) .{ }^{1} \mathrm{H}$ NMR $\left(400 \mathrm{MHz}, \mathrm{DMSO}-\mathrm{d}^{6}, \delta, \mathrm{ppm}\right): 4.31\left(-\mathrm{CH}_{2}\right), 7.85-7.93\left(\mathrm{~m}, \mathrm{Ar}-\mathrm{H}, \mathrm{NPG}^{-}\right)$,

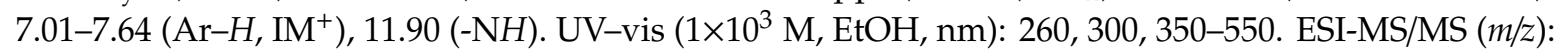
$294.1\left[\mathrm{C}_{13} \mathrm{H}_{13} \mathrm{~N}_{3} \mathrm{O}_{5}+3 \mathrm{H}^{+}\right]$.

\subsection{Single-Crystal X-ray Crystallography}

A Bruker SMART APEX CCD diffractometer (Billerica, MO, USA) was used to collect the single-crystal X-ray data at $100 \mathrm{~K}$ by employing graphite monochromatic MoK radiation (0.71073). The linear absorption coefficient, scattering factors for the atoms, and anomalous dispersion correction were referred from the International Table for X-ray crystallography [59]. The data integration and reduction were performed using SAINT software [60]. Empirical absorption correction was applied to collected reflections by using SADABS [61], and the space group was determined using XPREP [62].

The structure was solved via direct methods using SHELXTL-2016 and refined on F via full-matrix least-squares using the SIR-97 program package [63]. Only a few H atoms could be located in the difference Fourier maps of the structure. The positions of the remaining were calculated using idealized geometries (riding model) and assigned fixed isotropic displacement parameters. All the non- $\mathrm{H}$ atoms were refined anisotropically. The structure-refinement and crystal data are presented in Table 6 . The selective bond distance and angles are presented in Tables S1 and S2, respectively.

Table 6. Structure-refinement and crystal data for complex $\mathrm{IM}^{+}-\mathrm{NPG}^{-}$HYD.

\begin{tabular}{|c|c|}
\hline Parameters & $\mathrm{IM}^{+}-\mathrm{NPG}^{-}-\mathrm{HYD}$ \\
\hline Empirical formula & $\mathrm{C}_{13} \mathrm{H}_{13} \mathrm{~N}_{3} \mathrm{O}_{5}$ \\
\hline Formula weight & 291.27 \\
\hline Temperature (K) & $100(2)$ \\
\hline Crystal system & Monoclinic \\
\hline Space group & $\mathrm{C} 2 / \mathrm{c}$ \\
\hline a $(\AA)$ & $20.982(3)$ \\
\hline $\mathrm{b}(\AA)$ & $7.8082(10)$ \\
\hline$c(\AA)$ & $17.943(3)$ \\
\hline$\alpha\left(^{\circ}\right)$ & 90 \\
\hline$\beta\left({ }^{\circ}\right)$ & $119.808(7)$ \\
\hline$\gamma\left({ }^{\circ}\right)$ & 90 \\
\hline Volume $\left(\AA^{3}\right)$ & $2550.7(7)$ \\
\hline $\mathrm{Z}$ & 8 \\
\hline$\rho_{\text {calc }}\left(\mathrm{g} / \mathrm{cm}^{3}\right)$ & 1.5168 \\
\hline$\mu\left(\mathrm{mm}^{-1}\right)$ & 0.119 \\
\hline $\mathrm{F}(000)$ & 1216.7 \\
\hline Crystal size $\left(\mathrm{mm}^{3}\right)$ & $0.33 \times 0.21 \times 0.14$ \\
\hline Radiation & Mo $\mathrm{K} \alpha(\lambda=0.71073)$ \\
\hline $2 \theta$ range for data collection $\left({ }^{\circ}\right)$ & 5.68 to 50.1 \\
\hline Index ranges & $-28 \leq \mathrm{h} \leq 27,-10 \leq \mathrm{k} \leq 10,-23 \leq 1 \leq 23$ \\
\hline Reflections collected & 18701 \\
\hline Independent reflections & $2265\left(R_{\text {int }}=0.0943, R_{\text {sigma }}=0.0639\right)$ \\
\hline
\end{tabular}


Table 6. Cont.

\begin{tabular}{cc}
\hline Parameters & IM $^{+}-\mathbf{N P G}^{-}-\mathbf{H Y D}$ \\
\hline Data/restraints/parameters & $2265 / 0 / 193$ \\
Goodness-of-fit on $\mathrm{F}^{2}$ & 1.093 \\
Final R indexes [I $>=2 \sigma(\mathrm{I})]$ & $\mathrm{R}_{1}=0.0526, \mathrm{wR}_{2}=0.1094$ \\
Final R indexes (all data) & $\mathrm{R}_{1}=0.0669, \mathrm{wR}_{2}=0.1168$ \\
Largest diff. peak/hole/e $\AA^{-3}$ & $0.37 /-0.41$ \\
CCDC & 1915942 \\
\hline
\end{tabular}

GOF is defined as $\left\{\sum\left[w\left(F_{0}^{2}-F_{c}^{2}\right)\right] /(n-p)\right\}^{\frac{1}{2}}$ where $n$ denotes the number of data pieces and $p$ the number of parameters. $\mathrm{R}=\left\{\sum\left\|F_{0}|-| F_{c}\right\| / \sum\left|F_{0}\right|, w R_{2}=\left\{\sum w\left(F_{0}^{2}-F_{c}^{2}\right)^{2} / \sum w\left(F_{0}^{2}\right)^{2}\right\} \mid\right\}^{\frac{1}{2}}$.

\section{Computational Details}

The single-point calculation, full geometry optimization, and NBO analysis [64] were performed at DFT level of theory by using the M06-2X functional [65] (this functional was specifically developed to describe weak dispersion forces and noncovalent interactions) with the help of the Gaussian-09 program package [66]. The calculations were performed using cc-pVTZ basis sets [67] for all the atoms. All the geometry optimizations and TDDFT calculations were performed by employing the polarizable continuum model, CPCM (EtOH as solvent). No symmetry restrictions were applied during geometry optimization. Furthermore, the Hessian matrix was calculated analytically for the optimized structures to prove the location of the correct minima (no imaginary frequencies). The ${ }^{1} \mathrm{H}$ NMR spectrum of IM $^{+}-$NPG $^{-}-$HYD salt hydrated simulated using DFT/B3LYP/6-311+G(2d,p) and PBE0/Def2-TZVPP methods $[68,69]$. We have simulated the UV-vis spectrum (vertical excitation energies and oscillator strengths) of $\mathbf{I M}^{+}-\mathbf{N P G}^{-}-\mathbf{H Y D}$ using the CAM-B3LYP/cc-pVTZ method. The CAM-B3LYP functional is working well to calculate $\mathrm{CT}$ excitations by adopting the Coulomb-attenuating method as long-range corrected modification [70]. The electron-hole distribution, charge density difference (CDD), and inter-fragment $C T$ analysis between the singlet ground state $\left(\mathrm{S}_{0}\right)$ and singlet excited states $\left(\mathrm{S}_{n}\right.$, where $\mathrm{n}=1-20$ ) have been carried out with Multiwfn program [58] on the time-dependent wavefunction solution of $\mathbf{I M}^{+}-\mathrm{NPG}^{-}-\mathbf{H Y D}$ generated at the CAM-B3LYP/cc-pVTZ level of theory. In addition to the topological analysis of the electron-density distribution by using the QTAIM and ELF method, it has been performed employing the Multiwfn program. The Hirshfeld surface was mapped using Crystal Explorer [71] software using crystal structure coordinates of CIF files. The Cartesian atomic coordinates of the calculated equilibrium structures in ethanol are provided in the ESI-material.

Supplementary Materials: The following are available online at http://www.mdpi.com/2073-4352/10/2/91/s1, Figure S1: IR spectra of solid polycrystalline samples of imidazole (Purple), NPG (Blue) and IM ${ }^{+}-\mathrm{NPG}^{-}-\mathrm{HYD}^{-}$ (Red); Figure S2: DFT/M062X/6-31G** simulated IR spectrum of IM+-NPG--HYD; Figure S3: ESI-MS spectrum of polycrystalline samples of $\mathbf{I M}^{+}-\mathrm{NPG}^{-}-\mathbf{H Y D}$; Figure S4: Diagram illustrating the packing of $\mathbf{I M}^{+}-\mathrm{NPG}^{-}-\mathrm{HYD}$ in the unit cell at $100 \mathrm{~K}$ (H atoms have been omitted for clarity); Figure S5: DFT optimized structures in EtOH of both the configuration (a) A and (b) B of the $\mathbf{I M}^{+}-\mathbf{N P G}^{-}-\mathbf{H Y D}$ at the M062X/6-31G ${ }^{* *}$ level of theory. Bond distances given in angstrom $(\AA)$; Figure S6: Hirshfeld surface mapped with dnorm (left), shape index (middle),

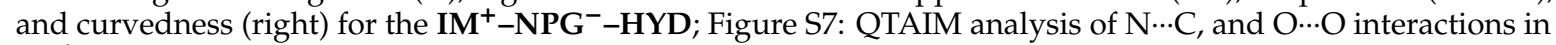
$\mathbf{I M}^{+}-\mathrm{NPG}^{-}-\mathbf{H Y D}$ (configuration A): (a) contour line plots of the electron density $\rho$, (b) contour line plots of the Laplacian distribution of electron density $\nabla^{2} \rho(\mathrm{r})$, the solid (red) and dashed (blue) lines corresponds to positive and negative values of $\nabla^{2} \rho(\mathrm{r})$ respectively, (c) surface maps of electron localization function (ELF), and (d) NCI surface between $\mathrm{IM}^{+}$and $\mathrm{NPG}^{-}$showing electron density for $\pi-\pi$ stacking interaction. Bond paths are shown as black lines, selected zero-flux surfaces, bond critical points, and BCPs, $(3,-1)$ are shown in blue; Figure S8: Showing charge transfer donor-acceptor moieties of both the configuration (a) A and (b) B of the $\mathbf{I M}^{+}-\mathbf{N P G}^{-}-\mathbf{H Y D}_{\text {. Pink }}$ arrow represents the dipole moment vector; Figure S9: Electron (green isosurface) and hole (blue isosurface) distribution between excited state and ground state of $\mathbf{I M}^{+}-\mathbf{N P G}^{-}-\mathbf{H Y D}$ for the absorptions at 297, 336, 427, and $443 \mathrm{~nm}$. Value of contour envelopes is $0.002 \mathrm{au}$; Figure S10: Electron (green isosurface) and hole (blue isosurface) distribution between excited state and ground state of $\mathbf{I M}^{+}-\mathbf{N P G}^{-}-\mathbf{H Y D}$ for the absorptions at 510, 530, 427, and 
$652 \mathrm{~nm}$. Value of contour envelopes is $0.002 \mathrm{au}$; Table S1: Bond Lengths in $\AA$ for IM $^{+}-\mathbf{N P G}^{-}-$HYD; Table S2: Bond Angles for $\mathbf{I M}^{+}-\mathbf{N P G}^{-}-\mathbf{H Y D}$; Table S3: Atomic Hirshfeld and atomic dipole moment $^{1}$ (ADC) corrected charges for $\mathbf{I M}^{\mathbf{+}}-\mathbf{N P G}^{-}-\mathbf{H Y D}$; Table S4: TD-DFT calculation for $\mathbf{I M}^{+}-\mathbf{N P G}^{-}-\mathbf{H Y D}$ at the CAM-B3LYP/cc-PVTZ theoretical level; calculated wavelength $(\lambda)$, oscillator strength $(f)$, transition energy $(E)$, and contributing orbitals to the transitions.

Author Contributions: Conceptualization, M.U. and R.A.K.; methodology, M.U. and R.A.K.; software, M.U.; validation, M.U., R.A.K., A.A. and S.T.; formal analysis, M.U., R.A.K., M.H.J., A.A. and S.T.; investigation, M.U., R.A.K., M.H.J., A.A. and S.T.; resources, R.A.K., M.H.J., A.A.; data curation, M.U.; writing-original draft preparation, M.U., R.A.K.; writing-review and editing, M.U., R.A.K., M.H.J., A.A. and S.T.; visualization, X.X.; supervision, R.A.K. and S.T.; project administration, A.A. and R.A.K.; funding acquisition, A.A. and R.A.K. All authors have read and agreed to the published version of the manuscript.

Funding: The authors are grateful to the Researchers Supporting Project number (RSP-2019/78), King Saud University, Riyadh, Saudi Arabia.

Conflicts of Interest: The authors declare no conflict of interest. The funders had no role in the design of the study; in the collection, analyses, or interpretation of data; in the writing of the manuscript, or in the decision to publish the results.

\section{References}

1. Whitesides, G.M.; Mathias, J.P.; Seto, C.T. Molecular self-assembly and nanochemistry: A chemical strategy for the synthesis of nanostructures. Science 1991, 254, 1312-1319. [CrossRef]

2. Lehn, J.M. From supramolecular chemistry towards constitutional dynamic chemistry and adaptive chemistry. Chem. Soc. Rev. 2007, 36, 151-160. [CrossRef]

3. Desiraju, G.R.; Parshall, G.W. Crystal Engineering: The Design of Organic. Solids. Mater. Sci. Monogr. 1989, 54.

4. Biradha, K. Crystal engineering: From weak hydrogen bonds to co-ordination bonds. CrystEngComm 2003, 5, 374-384. [CrossRef]

5. Xie, Z.; Yang, B.; Li, F.; Cheng, G.; Liu, L.; Yang, G.; Xu, H.; Ye, L.; Hanif, M.; Liu, S.; et al. Cross Dipole Stacking in the Crystal of Distyrylbenzene Derivative: The Approach toward High Solid-State Luminescence Efficiency. J. Am. Chem. Soc. 2005, 127, 14152-14153. [CrossRef] [PubMed]

6. Fang, X.; Yang, X.; Yan, D.J. Vapor-phase $\pi-\pi$ molecular recognition: A fast and solvent-free strategy towards the formation of co-crystalline hollow microtube with 1D optical waveguide and up-conversion emission. J. Mater. Chem. C 2017, 5, 1632-1637. [CrossRef]

7. Yan, D.P.; Delori, A.; Lloyd, G.O.; Friscic, T.; Day, G.M.; Jones, W.; Lu, J.; Wei, M.; Evans, D.G.; Duan, X. A cocrystal strategy to tune the luminescent properties of stilbene-type organic solid-state materials. Angew. Chem. Int. Ed. 2011, 50, 12483-12486. [CrossRef]

8. Chung, J.W.; You, Y.; Huh, H.S.; An, B.-K.; Yoon, S.-J.; Kim, S.H.; Lee, S.W.; Park, S.Y.J. Shear-and UV-induced fluorescence switching in stilbenic $\pi$-dimer crystals powered by reversible [2+2] cycloaddition. Am. Chem. Soc. 2009, 131, 8163-8172. [CrossRef]

9. Qin, Y.; Zhang, J.; Zheng, X.; Geng, H.; Zhao, G.; Xu, W.; Hu, W.; Shuai, Z.; Zhu, D. Charge-Transfer Complex Crystal Based on Extended- $\pi$-Conjugated Acceptor and Sulfur-Bridged Annulene: Charge-Transfer Interaction and Remarkable High Ambipolar Transport Characteristics. Adv. Mater. 2014, 26, 4093-4099. [CrossRef]

10. Zhang, J.; Tan, J.H.; Ma, Z.Y.; Xu, W.; Zhao, G.Y.; Geng, H.; Di, C.A.; Hu, W.P.; Shuai, Z.G.; Singh, K.; et al. Fullerene/sulfur-bridged annulene cocrystals: Two-dimensional segregated heterojunctions with ambipolar transport properties and photoresponsivity. J. Am. Chem. Soc. 2013, 135, 558-561. [CrossRef]

11. Zhang, J.; Geng, H.; Virk, T.S.; Zhao, Y.; Tan, J.H.; Di, C.A.; Xu, W.; Singh, K.; Hu, W.P.; Shuai, Z.G.; et al. Sulfur-Bridged Annulene-TCNQ Co-Crystal: A Self-Assembled “Molecular Level Heterojunction" with Air Stable Ambipolar Charge Transport Behavior. Adv. Mater. 2012, 24, 2603-2607. [CrossRef] [PubMed]

12. Kang, S.J.; Ahn, S.; Kim, J.B.; Schenck, C.; Hiszpanski, A.M.; Oh, S.; Schiros, T.; Loo, Y.-L.; Nuckolls, C. Using self-organization to control morphology in molecular photovoltaics. J. Am. Chem. Soc. 2013, 135, 2207-2212. [CrossRef] [PubMed]

13. Wuest, J.D. Co-crystals give light a tune-up. Nat. Chem. 2012, 4, 74-75. [CrossRef] [PubMed] 
14. Yan, D.; Yang, H.; Meng, Q.; Lin, H.; Wei, M. Two-Component Molecular Materials of 2,5-Diphenyloxazole Exhibiting Tunable Ultraviolet/Blue Polarized Emission, Pump-enhanced Luminescence, and Mechanochromic Response. Adv. Funct. Mater. 2014, 24, 587-594. [CrossRef]

15. Tsutsumi, J.Y.; Yamada, T.; Matsui, H.; Haas, S.; Hasegawa, T. Competition between charge-transfer exciton dissociation and direct photocarrier generation in molecular donor-acceptor compounds. Phys. Rev. Lett. 2010, 105, 226601. [CrossRef] [PubMed]

16. Vincent, V.M.; Wright, J.D. Competition between charge-transfer exciton dissociation and direct photocarrier generation in molecular donor-acceptor compounds. J. Chem. Soc. Faraday Trans. 1974, 70, 58-71. [CrossRef]

17. Horiuchi, S.; Ishii, F.; Kumai, R.; Okimoto, Y.; Tachibana, H.; Nagaosa, N.; Tokura, Y. Ferroelectricity near room temperature in co-crystals of nonpolar organic molecules. Nat. Mater. 2005, 4, 163-166. [CrossRef]

18. Tayi, A.S.; Shveyd, A.K.; Sue, A.C.H.; Szarko, J.M.; Rolczynski, B.S.; Cao, D.; Kennedy, T.J.; Sarjeant, A.A.; Stern, C.L.; Paxton, W.F.; et al. Room-temperature ferroelectricity in supramolecular networks of charge-transfer complexes. Nature 2012, 488, 485-489. [CrossRef]

19. Bosshard, C.; Wong, M.S.; Pan, F.; Gunter, P.; Gramlich, V. Self-assembly of an acentric co-crystal of a highly hyperpolarizable merocyanine dye with optimized alignment for nonlinear optics. Adv. Mater. 1997, 9, 554-557. [CrossRef]

20. Pan, F.; Wong, M.S.; Gramlich, V.; Bosshard, C.; Gunter, P.J. A Novel and Perfectly Aligned Highly Electro-Optic Organic Cocrystal of a Merocyanine Dye and 2,4-Dihydroxybenzaldehyde. J. Am. Chem. Soc. 1996, 118, 6315-6316. [CrossRef]

21. Morimoto, M.; Irie, M. A diarylethene cocrystal that converts light into mechanical work. J. Am. Chem. Soc. 2010, 132, 14172-14178. [CrossRef] [PubMed]

22. Braga, D.; Maini, L.; Grepioni, F. Mechanochemical preparation of co-crystals. Chem. Soc. Rev. 2013, 42, 7638-7648. [CrossRef] [PubMed]

23. Shimozawa, M.; Hashimoto, K.; Ueda, A.; Suzuki, Y.; Sugii, K.; Yamada, S.; Imai, Y.; Kobayashi, R.; Itoh, K.; Iguchi, S.; et al. Quantum-disordered state of magnetic and electric dipoles in an organic Mott system. Nat. Commun. 2017, 8, 1-6. [CrossRef]

24. Ueda, A.; Yamada, S.; Isono, T.; Kamo, H.; Nakao, A.; Kumai, R.; Nakao, H.; Murakami, Y.; Yamamoto, K.; Nishio, Y.; et al. Hydrogen-bond-dynamics-based switching of conductivity and magnetism: A phase transition caused by deuterium and electron transfer in a hydrogen-bonded purely organic conductor crystal. J. Am. Chem. Soc. 2014, 136, 12184-12192. [CrossRef] [PubMed]

25. Ueda, A.; Hatakeyama, A.; Enomoto, M.; Kumai, R.; Murakami, Y.; Mori, H. Modulation of a Molecular $\pi$-Electron System in a Purely Organic Conductor that Shows Hydrogen-Bond-Dynamics-Based Switching of Conductivity and Magnetism. Chem. Eur. J. 2015, 21, 15020-15028. [CrossRef] [PubMed]

26. Collini, E. Cooperative effects to enhance two-photon absorption efficiency: Intra-versus inter-molecular approach. Phys. Chem. Chem. Phys. 2012, 14, 3725-3736. [CrossRef]

27. Ono, T.; Sugimoto, M.; Hisaeda, Y. Multicomponent Molecular Puzzles for Photofunction Design: Emission Color Variation in Lewis Acid-Base Pair Crystals Coupled with Guest-to-Host Charge Transfer Excitation. J. Am. Chem. Soc. 2015, 137, 9519-9522. [CrossRef]

28. Narayanan, A.; Cao, D.; Frazer, L.; Tayi, A.S.; Blackburn, A.K.; Sue, A.C.-H.; Ketterson, J.B.; Stoddart, J.F.; Stupp, S.I. Ferroelectric Polarization and Second Harmonic Generation in Supramolecular Cocrystals with Two Axes of Charge-Transfer. J. Am. Chem. Soc. 2017, 139, 9186-9191. [CrossRef]

29. Zhu, W.; Zheng, R.; Fu, X.; Fu, H.; Shi, Q.; Zhen, Y.; Dong, H.; Hu, W. Revealing the Charge-Transfer Interactions in Self-Assembled Organic Cocrystals: Two-Dimensional Photonic Applications. Angew. Chem. Int. Ed. 2015, 54, 6785-6789. [CrossRef]

30. Mulliken, R.S. Molecular compounds and their spectra. II. J. Am. Chem. Soc. 1952, 74, 811-824. [CrossRef]

31. Thomas, L.H.; Jones, A.O.F.; Kallay, A.A.; McIntyre, G.J.; Wilson, C.C. Engineering short, strong, charge-assisted hydrogen bonds in benzoic acid dimers through cocrystallization with proton sponge. Cryst. Growth Des. 2016, 16, 2112-2122. [CrossRef]

32. Ward, M.D. Design of crystalline molecular networks with charge-assisted hydrogen bonds. Chem. Commun. 2005, 47, 5838-5842. [CrossRef] [PubMed]

33. Braga, D.; Grepioni, F. Intermolecular interactions in nonorganic crystal engineering. Acc. Chem. Res. 2000, 33, 601-608. [CrossRef] [PubMed] 
34. Aaker€oy, C.B.; Beatty, A.M.; Lorimer, K.R. Charge-assisted hydrogen bonds and halogen-halogen interactions in organic salts: Benzylammonium benzoates and pentafluorobenzoates. Struct. Chem. 1999, 10, $229-242$. [CrossRef]

35. Braga, D.; Draper, S.M.; Champeil, E.; Grepioni, F. Inorganic-organometallic crystal synthesis. The role of charge-assisted $\mathrm{C}-\mathrm{H} \ldots \mathrm{O}$ and $\mathrm{C}-\mathrm{H} \ldots \mathrm{Cl}$ hydrogen bonds in crystalline $\left[\left(\eta 5-\mathrm{C}_{5} \mathrm{H}_{5}\right){ }_{2 \mathrm{Co}} \mathrm{CH}_{2} \mathrm{PO}_{4}\right] \cdot 3 \mathrm{H}_{2} \mathrm{O}$ and $\left[\left(\eta 6-\mathrm{C}_{6} \mathrm{H}_{5} \mathrm{Me}\right) 2 \mathrm{Cr}\right][\mathrm{Cl}]$. J. Organomet. Chem. 1999, 573, 73-77. [CrossRef]

36. Bankiewicz, B.; Matczak, P.; Palusiak, M. Electron density characteristics in bond critical point (QTAIM) versus interaction energy components (SAPT): The case of charge-assisted hydrogen bonding. J. Phys. Chem. A 2012, 116, 452-459. [CrossRef]

37. Matczak, P. Intramolecular $\mathrm{C}-\mathrm{H} \cdots \mathrm{H}-\mathrm{C}$ contacts in diheteroaryl ketones and thioketones: A theoretical analysis. Bull. Chem. Soc. Jpn. 2016, 89, 92-102. [CrossRef]

38. Silverstein, R.M.; Silverstein, G.C. Bassler Spectrometric Identification of Organic Compounds. J. Chem. Educ. 1962, 39, 546. [CrossRef]

39. Ganduri, R.; Swain, D.; Cherukuvada, S.; Row, T.N.G. Role of functionalities in structural analogues urocanic acid and l-histidine, toward the formation of anhydrous and hydrated molecular salts. Cryst. Growth Des. 2019, 19, 1845-1852. [CrossRef]

40. Gunnam, A.; Suresh, K.; Nangia, A. Salts and salt cocrystals of the antibacterial drug pefloxacin. Cryst. Growth Des. 2018, 18, 2824-2835. [CrossRef]

41. Oomens, J.; Steill, J.D. Free carboxylate stretching modes. J. Phys. Chem. 2008, 112, 3281-3283. [CrossRef] [PubMed]

42. Steill, J.D.; Oomens, J. Gas-phase deprotonation of p-hydroxybenzoic acid investigated by IR spectroscopy: Solution-phase structure is retained upon ESI. J. Am. Chem. Soc. 2009, 131, 13570-13571. [CrossRef] [PubMed]

43. Arenas-García, J.R.; Ruiz, D.H.; Vasquez, K.M.; Rojas, H.M.; Hopfl, H. Modification of the supramolecular hydrogen-bonding patterns of acetazolamide in the presence of different cocrystal formers: 3:1, 2:1, 1:1, and 1:2 cocrystals from screening with the structural isomers of hydroxybenzoic acids, aminobenzoic acids, hydroxybenzamides, aminobenzamides, nicotinic acids, nicotinamides, and 2, 3-dihydroxybenzoic acids. Cryst. Growth Des. 2012, 12, 811-824.

44. Gao, L.; Zhang, X.-R.; Chen, Y.-F.; Liao, Z.-L.; Wang, Y.-Q.; Zou, X.-Y. A new febuxostat imidazolium salt hydrate: Synthesis, crystal structure, solubility, and dissolution study. J. Mol. Struct. 2019, 1176, 633-640. [CrossRef]

45. Mandal, A.; Rissanen, K.; Mal, P. Unravelling substitution effects on charge transfer characteristics in cocrystals of pyrene based donors and 3, 5-dinitrobenzoic acid. CrystEngComm 2019, 21, 4401-4408. [CrossRef]

46. Mandal, A.; Swain, P.; Nath, B.; Sau, S.; Mal, P. Unipolar to ambipolar semiconductivity switching in charge transfer cocrystals of 2, 7-di-tert-butylpyrene. CrystEngComm 2019, 21, 981-989. [CrossRef]

47. Usman, R.; Khan, A.; Wang, M.; Luo, Y.; Sun, W.; Sun, H.; Du, C.; He, N. Investigation of charge-transfer interaction in mixed stack donor-acceptor cocrystals toward tunable solid-state emission characteristics. Cryst. Growth Des. 2018, 18, 6001-6008. [CrossRef]

48. Zhu, W.; Zheng, R.; Zhen, Y.; Yu, Z.; Dong, H.; Fu, H.; Shi, Q.; Hu, W. Rational design of charge-transfer interactions in halogen-bonded co-crystals toward versatile solid-state optoelectronics. J. Am. Chem. Soc. 2015, 137, 11038-11046. [CrossRef]

49. Bader, R. Atoms in Molecules; Oxford University Press: Oxford, UK, 1994; Available online: https://global.oup. com/academic/product/atoms-in-molecules-9780198558651?cc=sa\&lang=en\& (accessed on 5 February 2020).

50. Bader, R.F.W. A quantum theory of molecular structure and its applications. Chem. Rev. 1991, 91, 893-928. [CrossRef]

51. Koch, U.; Popelier, P. Characterization of $\mathrm{CHO}$ hydrogen bonds on the basis of the charge density. J. Phys. Chem. A 1995, 99, 9747-9754. [CrossRef]

52. Rozas, I.; Alkorta, I.; Elguero, J. Behavior of ylides containing N, O, and C atoms as hydrogen bond acceptors. J. Am. Chem. Soc. 2000, 122, 11154-11161. [CrossRef]

53. Espinosa, E.; Alkorta, I.; Elguero, J.; Molins, E. From weak to strong interactions: A comprehensive analysis of the topological and energetic properties of the electron density distribution involving $\mathrm{X}-\mathrm{H} \cdots \mathrm{F}-\mathrm{Y}$ systems. J. Chem. Phys. 2002, 117, 5529-5542. [CrossRef]

54. Espinosa, E.; Molins, E.; Lecomte, C. Hydrogen bond strengths revealed by topological analyses of experimentally observed electron densities. Chem. Phys. Lett. 1998, 285, 170-173. [CrossRef] 
55. Vener, M.V.; Egorova, A.N.; Churakov, A.V.; Tsirelson, V.G. Intermolecular hydrogen bond energies in crystals evaluated using electron density properties: DFT computations with periodic boundary conditions. J. Comput. Chem. 2012, 33, 2303-2309. [CrossRef] [PubMed]

56. Park, S.K.; Varghese, S.; Kim, J.H.; Yoon, S.-J.; Kwon, O.K.; An, B.-K.; Gierschner, J.; Park, S.Y. Tailor-made highly luminescent and ambipolar transporting organic mixed stacked charge-transfer crystals: An isometric donor-acceptor approach. J. Am. Chem. Soc. 2013, 135, 4757-4764. [CrossRef] [PubMed]

57. Zhu, L.; Yi, Y.; Li, Y.; Kim, E.-G.; Coropceanu, V.; Brédas, J.-L. Prediction of remarkable ambipolar charge-transport characteristics in organic mixed-stack charge-transfer crystals. J. Am. Chem. Soc. 2012, 134, 2340-2347. [CrossRef] [PubMed]

58. Lu, T.; Chen, F.-W. Multiwfn: A multifunctional wavefunction analyzer. J. Comput. Chem. 2012, 33, 580-592. [CrossRef] [PubMed]

59. Cromer, D.T.; Waber, J.T. International Tables for X-Ray Crystallography, Kynoch. Birm. Engl. 1952, 3, 257-269.

60. Sheldrick, G.M. SAINT (Version 6.02), SADABS (Version 2.03); Bruker AXS: Madison, WI, USA, 2002.

61. Sheldrick, G.M. SADABS, Program for Empirical Absorption Correction of Area Detector Data. Available online: https://www.scienceopen.com/document?vid=5cab3651-c60c-4e6d-89cc-c55396e9e2dc (accessed on 5 February 2020).

62. Sheldrick, G.M. SAINT and XPREP, version 5.1; Siemens Industrial Automation Inc.: Madison, WI, USA, 1995.

63. Sheldrick, G.M. SHELXTL, version 5.1; Bruker Analytical X-ray Instruments Inc.: Madison, WI, USA, 1998; Volume 4, p. 18.

64. Glendening, E.D.; Reed, A.E.; Carpenter, J.E.; Weinhold, F. Gaussian 09 Citation; Gaussian. Inc.: Wallingford, CT, USA, 2009.

65. Zhao, Y.; Truhlar, D.G. The M06 suite of density functionals for main group thermochemistry, thermochemical kinetics, noncovalent interactions, excited states, and transition elements: Two new functionals and systematic testing of four M06-class functionals and 12 other functionals. Theor. Chem. Acc. 2008, 120, 215-241.

66. Frisch, M.J.T.; Trucks, G.W.; Schlegel, H.B.; Scuseria, G.E.; Robb, M.A.C.; Cheeseman, J.R.; Scalmani, G.; Barone, V.; Mennucci, G.A.N.B.; Petersson, H.; et al. Gaussian 09 Citation. Available online: https: //gaussian.com/g09citation/ (accessed on 5 February 2020).

67. Dunning, T.H., Jr. Gaussian basis sets for use in correlated molecular calculations. I. The atoms boron through neon and hydrogen. J. Chem. Phys. 1989, 90, 1007. [CrossRef]

68. Adamo, C.; Scuseria, G.E.; Barone, V. Accurate excitation energies from time-dependent density functional theory: Assessing the PBE0 model. J. Chem. Phys. 1999, 111, 2889. [CrossRef]

69. Flaig, D.; Maurer, M.; Hanni, M.; Braunger, K.; Kick, L.; Thubauville, M.; Ochsenfeld, C. Benchmarking hydrogen and carbon NMR chemical shifts at HF, DFT, and MP2 levels. J. Chem. Theory Comput. 2014, 10, 572-578. [CrossRef] [PubMed]

70. Yanai, T.; Tew, D.P.; Handy, N.C. A new hybrid exchange-correlation functional using the Coulomb-attenuating method (CAM-B3LYP). Chem. Phys. Lett. 2004, 393, 51-57. [CrossRef]

71. Spackman, M.A.; Jayatilaka, D. Hirshfeld surface analysis. CrystEngComm. 2009, 11, 19-32. [CrossRef]

(C) 2020 by the authors. Licensee MDPI, Basel, Switzerland. This article is an open access article distributed under the terms and conditions of the Creative Commons Attribution (CC BY) license (http://creativecommons.org/licenses/by/4.0/). 